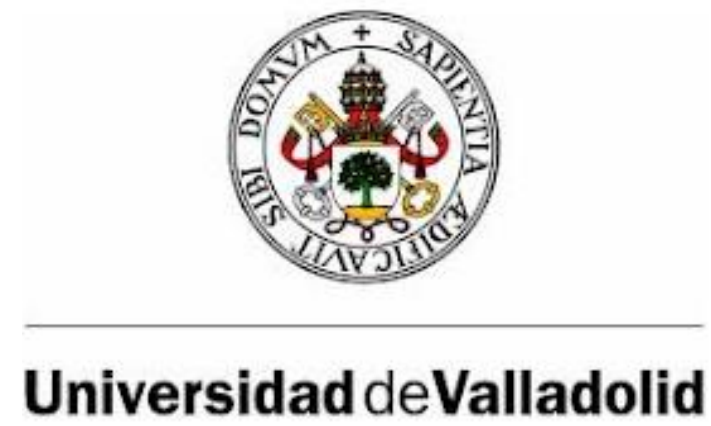

Facultad de Medicina

Grado en Logopedia

Trabajo de Fin de Grado

Curso 2019-2020

\title{
NUEVAS LÍNEAS DE TRATAMIENTO \\ LOGOPÉDICO DE LAS AFASIAS: \\ LA TERAPIA INTENSIVA
}

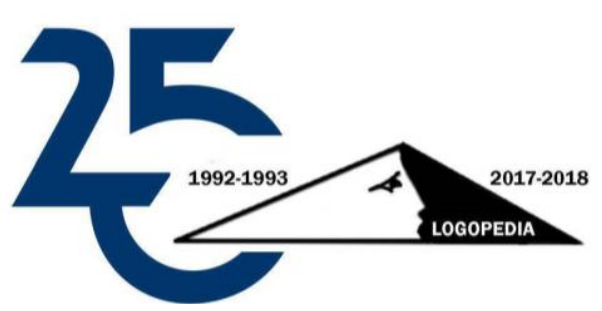

Autora: ELENA SÁNCHEZ GARCÍA

Tutora académica: PATRICIA MURCIEGO RUBIO 


\section{ÍNDICE}

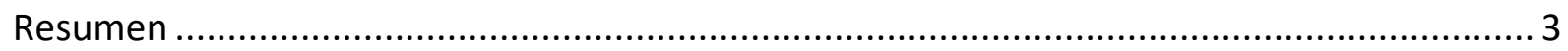

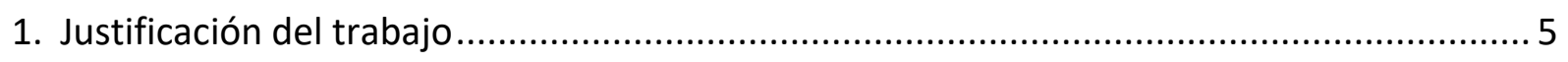

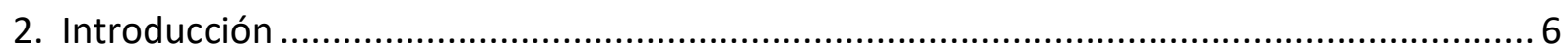

2.1. Conceptualización de las afasias .......................................................... 6

2.2. Clasificación de las afasias....................................................................... 7

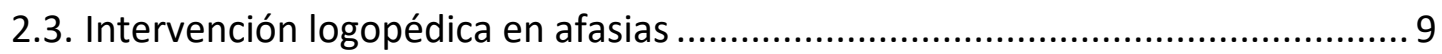

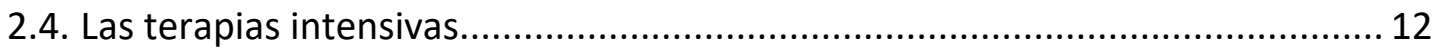

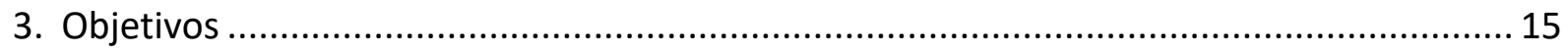

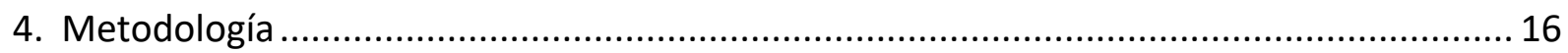

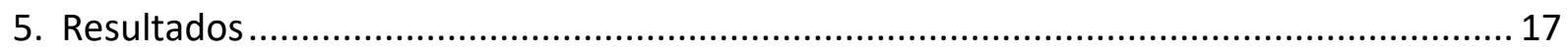

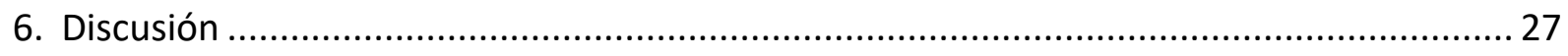

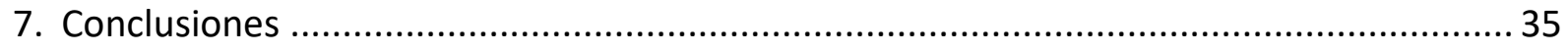

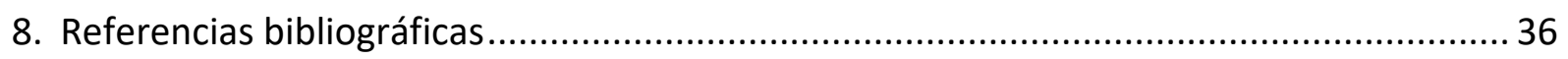

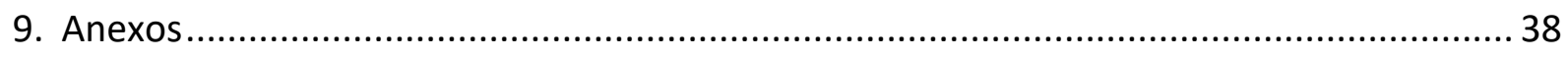

Anexo I. Principales características de los síndromes afásicos ............................... 38

Anexo II. Listado de terapias aplicadas en los ensayos clínicos de la revisión

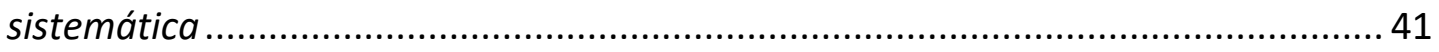




\section{RESUMEN}

Introducción: Existen numerosas evidencias de los beneficios de la intervención logopédica en pacientes con afasia; no obstante, aún se continúa investigando qué factores aumentan la eficacia de un tratamiento sobre otro. La aplicación de terapias intensivas ha visto incrementado su interés por parte de la comunidad científica debido a sus resultados positivos.

Objetivos: Esta revisión pretende actualizar los conceptos y evidencias sobre la intervención logopédica intensiva en pacientes con afasia.

Metodología: Se ha realizado una revisión de 59 documentos científicos, de los cuales 22 son ensayos clínicos que aplican una intervención logopédica en pacientes con afasia.

Resultados y discusión: La mayoría de los ensayos clínicos revisados encuentran eficaces las terapias intensivas, especialmente aquellas de carácter interactivo aplicadas en pacientes con afasia crónica. Los objetivos de estas investigaciones se centran en concretar diversos parámetros para optimizar los resultados de estos tratamientos y comprobar su viabilidad en diversas circunstancias.

Conclusiones: Las terapias intensivas parecen albergar un gran potencial para la rehabilitación de pacientes afásicos. Se precisan más investigaciones para determinar la dosis óptima de intensidad, el enfoque metodológico más beneficioso, la viabilidad en etapas agudas y las características de los pacientes y de la afasia que influyen en el éxito de la terapia.

Palabras clave: Afasia, daño cerebral adquirido, terapias intensivas, Constraint-Induced Aphasia Therapy (CIAT), Rehabilitación Grupal Intensiva de la Afasia (REGIA). 


\section{ABSTRACT}

Introduction: Extensive evidence support the beneficial effect of speech therapy in patients with aphasia; nevertheless, research is still ongoing to determine which factors increase the efficacy of one treatment over another. The application of intensive therapies has been gaining interest from the scientific community due to its positive results.

Aims: This review attempts to update the notions and evidence regarding intensive speech therapy in patients with aphasia.

Method: A review of 59 scientific documents has been carried out, among which 22 are clinical trials applying a speech therapy intervention in patients with aphasia.

Results and discussion: Most of the clinical trials reviewed find intensive therapies effective, especially those of an interactive nature applied to chronic aphasia patients. The objectives of these investigations are focused on determining different parameters to optimise the results of these treatments and verify their viability under diverse circumstances.

Conclusions: Intensive therapies seem to harbour great potential for the rehabilitation of aphasic patients. Further research is needed to determine the optimal dose intensity, the most beneficial methodological approach, the feasibility in acute stages, and the characteristics of both patients and aphasias that influence on therapy success.

Keywords: Aphasia, acquired brain injury, intensive therapies, Constraint-Induced Aphasia Therapy (CIAT), Rehabilitación Grupal Intensiva de la Afasia (REGIA). 


\section{JUSTIFICACIÓN DEL TRABAJO}

En este documento se presenta el Trabajo de Fin de Grado correspondiente al cuarto curso del Grado en Logopedia de la Universidad de Valladolid.

El desarrollo del trabajo partió de una preferencia temática: el daño neurológico. La idea de base fue, por tanto, un trabajo de investigación relacionado con la intervención logopédica en pacientes con daño cerebral adquirido. Planteé esta idea preliminar y general a mi tutora, que me comentó diversos temas referentes de actualidad. Entre ellos, me habló de las terapias intensivas, programas de intervención logopédica destinados a personas con afasia basados en la práctica masiva durante varias horas semanales; también me nombró los autores punteros en el tema, entre ellos, un investigador español que está popularizando esta técnica a nivel nacional.

A partir de estos datos, comencé a investigar, y ciertamente llamó mi atención que la clave del éxito de un programa de rehabilitación pudiera encontrarse en la intensidad y no tanto en el enfoque o metodología de la intervención. Considero estos hallazgos de gran relevancia a la hora de plantear la intervención logopédica en pacientes con daño neurológico. Por ello, decidí continuar revisando publicaciones relacionadas y realizar una revisión sistemática sobre ensayos clínicos recientes que aplicasen dichas técnicas. 


\section{INTRODUCCIÓN}

\subsection{Conceptualización de las afasias}

La Federación Española de Daño Cerebral ${ }^{1}$ (FEDACE) define el daño cerebral adquirido (DCA) como "una lesión que se produce en las estructuras cerebrales de forma súbita en personas que, habiendo nacido sin ningún tipo de daño en el cerebro, sufren en un momento posterior de su vida lesiones en el mismo como consecuencia de un accidente o una enfermedad". EI paciente con daño cerebral adquirido podrá presentar síntomas a nivel de cualquiera de las áreas y funciones cerebrales, entre ellas, el lenguaje y la comunicación. Cuando una persona con daño cerebral adquirido ve afectada su capacidad de comunicarse y de expresarse a través del lenguaje hablamos de afasia. Debe diferenciarse de otros problemas de la comunicación de origen neurógeno como la disartria, que se corresponde con la 'afectación del habla por debilidad, lentitud o descoordinación muscular' ${ }^{1,2}$.

El término afasia fue introducido por el médico francés Trousseau en el año $1864^{3}$. Según la Asociación Americana del Habla, Lenguaje y Audición (ASHA) ${ }^{4}$, la afasia es "un trastorno neurógeno adquirido del lenguaje que resulta de una lesión en el cerebro". La afasia implica la pérdida total o parcial de funciones cerebrales previamente desarrolladas con normalidad, concretamente la expresión y comprensión del lenguaje, tanto en la modalidad oral como en la escrita ${ }^{1,4}$, afectándose de manera selectiva cualquiera de los niveles lingüísticos (fonéticofonológico, morfosintáctico, léxico-semántico y pragmático $)^{5}$. Además, pueden verse comprometidos otros procesos cognitivos imprescindibles para el correcto funcionamiento del lenguaje, como la memoria verbal a corto plazo y la atención ${ }^{2,6}$.

La afasia se puede producir por cualquier etiología que afecte al tejido cerebral en las zonas relacionadas directa e indirectamente con el funcionamiento del lenguaje ${ }^{6}$. La causa más habitual son los accidentes cerebrovasculares (ACV); entre el $21 \%$ y el $38 \%$ de los ictus ocasionan dificultades del lenguaje o afasia ${ }^{2,7}$. Otros factores que pueden originar una afasia son los traumatismos craneoencefálicos (TCE), tumores, infecciones intracraneales, epilepsia, procedimientos quirúrgicos y enfermedades neurodegenerativas ${ }^{2,5}$. En pacientes diestros, las afasias afectan habitualmente al hemisferio izquierdo (aproximadamente el $90 \%$ ). Las topografías más habituales son la corteza perisilviana y las estructuras anatómicas adyacentes 
irrigadas por la arteria cerebral media, entre ellas, los ganglios basales, la cápsula interna y la sustancia blanca periventricular ${ }^{2,6,8}$.

Los perfiles afásicos son heterogéneos en relación con la severidad y los componentes del lenguaje afectados; los síntomas pueden variar desde dificultades ocasionales de acceso al léxico hasta la pérdida total de comunicación verbal ${ }^{9}$. De esta manera, la afasia puede acarrear implicaciones severas desde el punto de vista social, personal y económico, dado que el lenguaje constituye una parte integral del individuo como vehículo del pensamiento y de la comunicación con el entorno ${ }^{6}$. Algunos autores catalogan la afasia como la secuela más devastadora causada por una lesión cerebra| ${ }^{2,6,9}$.

Está contrastado que los pacientes siempre presentan algún progreso y muchos consiguen una recuperación total o muy significativa ${ }^{9,10}$. Los estudios sobre la recuperación de las afasias por ACV han determinado que las mejoras más sustanciales se producen en los primeros dos o tres meses, alcanzando los mejores resultados tras el año ${ }^{2,10}$. La recuperación temprana en los casos de afasia de etiología repentina ( $\mathrm{ACV}, \mathrm{TCE} . .$.$) parece estar relacionada con diferentes$ mecanismos de recuperación del tejido, mientras que en fases posteriores, la mejora del cuadro depende de diversos procesos de reorganización y compensación de las funciones cognitivas en el cerebro ${ }^{8}$. Varios factores influyen en el pronóstico de la recuperación de la afasia. Por lo general, tienen peor pronóstico las lesiones de etiología vascular (especialmente las de origen isquémico) o tumoral y aquellas en las que persisten graves dificultades articulatorias o comprensivas tras el primer mes ${ }^{6,11}$. Existen otros factores como el lugar y tamaño de la lesión, el perfil afásico, la edad, el sexo o el nivel educativo previo del individuo, pero el estudio de la interacción de estos indicadores es complejo ${ }^{10,11}$.

\subsection{Clasificación de las afasias}

La clasificación tradicional de las afasias está concebida desde un punto de vista localizacionista, enmarcada en el objetivo de correlacionar el lugar de la lesión cerebral y las alteraciones del lenguaje, resultando unas agrupaciones sindrómicas de pacientes con una topografía cerebral y síntomas lingüísticos similares $3,5,6,12,13$. Esta tendencia fue iniciada por los estudios de Broca y Wernicke en la segunda mitad del siglo XIX, formalizándose en el modelo conexionista de Ludwig Lichtheim (1885), en el que se contemplan siete clases de afasia: afasia de Broca, afasia de Wernicke, afasia de conducción, afasia transcortical motora, 
afasia transcortical sensorial, afasia motora subcortical y afasia sensorial subcortical ${ }^{3,5,13}$. En contraposición, surgieron en los años siguientes concepciones más holísticas y globales sobre el cerebro y las alteraciones del lenguaje, en favor de un punto de vista más psicológico que neuroanatómico ${ }^{12,14}$.

En el marco de esta controversia, se populariza una tendencia intermedia entre ambos enfoques: el modelo de Luria (1947). La clasificación de Luria desarrolla las ideas del lingüista Roman Jakobson, que señaló dos formas básicas de afasias: paradigmáticas (trastorno de similitud) y sintagmáticas (trastorno de contigüidad). Las primeras restringen la capacidad del paciente para seleccionar las palabras (correspondiente con la afasia de Wernicke) y las segundas se relacionan con la pérdida de la capacidad para combinar los elementos lingüísticos (correspondiente con la afasia de Broca) ${ }^{15}$. Luria desarrolla un modelo que concibe el lenguaje como un sistema funcional complejo, clasificando las afasias desde un punto de vista más lingüístico, pero considerando también la localización de las lesiones ${ }^{12}$.

En el año 1960 surgió la clasificación dominante en la bibliografía actual, el modelo neoconexionista propuesto por Norman Geschwind y sus colaboradores de la escuela de Boston, que retoma la interpretación de Wernicke-Lichtheim ${ }^{5,14}$. El grupo de Boston explica las variedades de afasias basándose en la presencia o ausencia de fluidez, comprensión, denominación y capacidad de repetición, diferenciando ocho síndromes afásicos: afasia de Broca, afasia de Wernicke, afasia de conducción, afasia global, afasia transcortical motora, afasia transcortical sensorial, afasia transcortical mixta y afasia anómica ${ }^{5,8}$. En el Anexo / se incluye una tabla resumen extraída del manual de afasias de González y González ${ }^{5}$ que resume las principales características de estos ocho síndromes afásicos, ya que, a pesar de tratarse de una clasificación clásica, es la más utilizada en el marco de la investigación actual.

A raíz de este resurgimiento del enfoque clásico, la investigación sobre las afasias se desarrolló notoriamente durante la segunda mitad del siglo xx. El advenimiento de las técnicas de neuroimagen a partir de la década de los 70 permitió comenzar a visualizar la actividad cerebral durante la realización de diferentes tareas verbales y, por tanto, establecer correlaciones clínico-anatómicas más precisas, desafiando algunos de los hallazgos tradicionales sobre los síndromes afásicos ${ }^{12,14,15}$. De esta manera, actualmente se trabaja en 
virtud de la integración progresiva del conocimiento en el marco de la neuropsicología clínica, aunque la síntesis de los recientes hallazgos es una tarea compleja ${ }^{12}$.

Se han propuesto varias clasificaciones más recientes, no obstante, todas parecen incluir perfiles clínicos muy similares a los anteriormente descritos, a pesar de que se les otorgue diferentes denominaciones ${ }^{14}$. Como indica Berthier ${ }^{2}$, para clasificar un síndrome afásico desde el punto de vista clínico se suele atender a criterios dicotómicos, considerando tres dominios lingüísticos clásicos: la fluencia (afasias fluentes correlacionadas con lesiones en los lóbulos temporal y parietal; afasias no fluentes correlacionadas con lesiones en el lóbulo frontal), las tareas de repetición (repetición afectada asociada a lesiones perisilvianas; repetición preservada asociada a lesiones extrasilvianas) y la comprensión (alteración de la comprensión relacionada con lesiones posteriores; comprensión preservada relacionada con alteraciones anteriores).

Aunque los criterios dicotómicos y los síndromes afásicos clásicos han resultado útiles clínicamente, han sido recientemente criticados ${ }^{2}$. Hay que considerar que la variabilidad de la semiología afásica es tal que, a nivel práctico, pocos pacientes se ajustan a alguno de los perfiles tradicionales ${ }^{13}$. Por estas razones, tendencias actuales abogan por un abordaje clínico que integre a su vez las ideas de la neuropsicología cognitiva del lenguaje,6,12,13. Esta rama considera que la afasia supone la alteración de alguno de los subniveles del sistema de procesamiento del lenguaje, analizando los componentes dañados en cada caso particular partiendo del funcionamiento verbal normal ${ }^{12}$. De esta manera, integrando ambos enfoques, se conseguiría un conocimiento más amplio de la naturaleza de las alteraciones lingüísticas, favoreciendo el diseño de estrategias individualizadas para cada paciente ${ }^{2,6,13}$.

\subsection{Intervención logopédica en afasias}

Dentro del ámbito de la rehabilitación de los pacientes con DCA, se habla de rehabilitación neuropsicológica ${ }^{16}$. Si nos centramos en el lenguaje, uno de los procesos más frecuentemente afectados, el logopeda será el especialista encargado de esta rehabilitación, enmarcada dentro de las SLT (Speech and Language Therapy), terapias del habla y el lenguaje, denominadas así por la comunidad científica ${ }^{9,16,17}$. 
Como indica Peña-Casanova ${ }^{6}$ en lo concerniente a la rehabilitación de la afasia, "hay métodos para todos los gustos" ${ }^{317}$. Para justificar y sintetizar esta heterogeneidad en las metodologías de rehabilitación, este autor describe tres amplios enfoques de intervención: pedagógica, fisiopatológica cognitiva y estimulación ecológica intensiva. La primera de ellas partiría de los síntomas observados en el paciente; la segunda se corresponde con el enfoque de la neuropsicología cognitiva, aplicando métodos específicos para rehabilitar el mecanismo neurolingüístico afectado en cada paciente; finalmente, la aproximación ecológica se enfoca desde un punto de vista intensivo, atendiendo a la mejora de la capacidad comunicativa del paciente a través de mecanismos neurobiológicos.

A pesar de esta diversidad, los principios subyacentes de la terapia son relativamente similares ${ }^{17}$. Desde los estudios clásicos de Luria tras la Segunda Guerra Mundial, la intervención con pacientes con DCA ha sido un tema de interés, especialmente en relación con el lenguaje ${ }^{15}$. A mediados del siglo Xx, Butfield y Zangwill (citado por De Noreña et al. ${ }^{16}$ ) indicaron los tres mecanismos básicos de recuperación de las funciones cerebrales perdidas que sustentan la rehabilitación neuropsicológica, estrategias que continúan fundamentando las terapias actuales; estas son la restitución o restauración, la compensación y la sustitución. La restitución se centra en la estimulación directa del déficit o función perdida, la compensación en potenciar las funciones preservadas para suplir el daño, y la sustitución en el empleo de apoyos externos como alternativa a la función perdida.

De forma general, independiente de la metodología utilizada, la meta principal del tratamiento siempre deberá ser "dotar al paciente de una comunicación funcional” ${ }^{1}$. Ardila ${ }^{15}$ dispone cinco objetivos generales de la intervención: mantener al paciente verbalmente activo; reaprender el lenguaje; suministrar estrategias para mejorar el lenguaje; enseñar a la familia a comunicarse con el paciente; y dar apoyo psicológico al paciente. A su vez, la Federación Española de Daño Cerebral ${ }^{1}$ (FEDACE) establece el plan terapéutico que debe seguir el logopeda con un paciente afásico: (1) decidir cuál es el problema a tratar; (2) decidir cómo conducir el tratamiento; (3) definir por qué se han escogido los métodos; (4) averiguar, medir y registrar todo lo que acontece; y (5) especificar la utilidad, para el paciente, de la mejoría en la tarea escogida. Por otro lado, la intervención en afasias se da generalmente de manera individual ${ }^{5}$, aunque ciertamente, la terapia grupal ofrece algunas posibilidades ventajosas con estos pacientes, como la interacción social y un mayor factor motivacional ${ }^{6}$. 
Puesto que los cimientos de la intervención parecen estar relativamente definidos, el tema de debate actual es determinar qué factores hacen que una terapia sea más eficaz que otra ${ }^{18}$. El efecto beneficioso de la terapia frente a su ausencia está ampliamente demostrado, tanto en pacientes subagudos como en $\operatorname{cróni}^{9}{ }^{9,16}$; sin embargo, no se ha contrastado ningún tratamiento universalmente aceptado $^{9}$, lo que justifica la heterogeneidad de enfoques $y$ opiniones en función de la tendencia de cada autor.

Por un lado, Pulvermüller et al. ${ }^{19}$ realizan una dicotomía entre "terapias convencionales o estándar" y las terapias aplicadas de forma intensiva (3 o 4 horas al día durante 10 días), atribuyendo mayores limitaciones a las primeras. Son numerosos los estudios que avalan el factor intensidad en la rehabilitación de pacientes afásicos ${ }^{9,16}$; este será el tema abordado en este trabajo y se describirá con mayor profundidad posteriormente.

De Noreña et al. ${ }^{16}$ postula que las terapias que probablemente supongan una mayor innovación sobre las tradicionales sean aquellas que se centran en la funcionalidad del paciente y no tanto en el déficit; es decir, en el mecanismo de compensación por encima del mecanismo de restitución. Asimismo, respalda algunos programas específicos de rehabilitación enfocados en la restitución, pero más sofisticadas y actuales, como la denominada Constraint-Induced Aphasia Therapy (CIAT), terapia de carácter intensivo que también ocupará un lugar central en este trabajo.

A su vez, Peña-Casanova ${ }^{6}$ indica que las terapias más recientes están integrando una intervención más global (psicológico, social e individual), en las que el logopeda desempeña un papel adicional de acompañante del paciente al enfrentarse con el problema comunicativo, otorgando especial importancia a los aspectos emocionales y motivacionales. Siguiendo esta línea, De Noreña ${ }^{16}$ afirma que la rehabilitación neuropsicológica está actualmente progresando hacia un enfoque más funcional, poniendo énfasis en los aspectos más relevantes para el paciente y su entorno y en la utilidad de los aprendizajes en su vida cotidiana.

El uso de métodos audiovisuales es también un campo prometedor en el ámbito de la rehabilitación de pacientes afásicos ${ }^{6,18,20}$. Las terapias electrónicas (e-therapies) suponen una buena opción para extender la intervención al domicilio y ahorrar tiempo al terapeuta, sin pecar tampoco de sustituir completamente la relación interpersonal con el mismo6; además, 
hay un gran repertorio disponible ${ }^{18}$. Algunos de los softwares con mayor nivel de evidencia son Power-Afa ${ }^{20}$ y StepByStep ${ }^{18}$. Lo mismo ocurre con otros tratamientos cuya eficacia se está contrastando de forma conjunta con la intervención logopédica, como son los medicamentos ${ }^{2,20}$ y las técnicas de estimulación cerebral no invasiva ${ }^{20}$.

\subsection{Las terapias intensivas}

Como se ha comentado anteriormente, una de las metodologías que establecía PeñaCasanova ${ }^{6}$ en lo referente a la rehabilitación de la afasia era la aproximación ecológica estimulativa intensiva. La intervención logopédica intensiva o masiva ya se mencionó en los estudios clásicos de la rehabilitación neuropsicológica de personas con DCA, pero el interés de la comunidad científica no se instauró hasta los últimos años de la década de los $90^{21}$. En el año 2001, el investigador alemán Friedemann Pulvermüller puso en práctica junto a sus colaboradores $^{19}$ una nueva técnica terapéutica, la denominada Constraint-Induced Aphasia Therapy (CIAT), que actualmente podría considerarse la formalización del enfoque ecológico intensivo ${ }^{6}$. La CIAT se caracteriza principalmente por ser una terapia intensiva (3-4 horas al día durante 10 días, como mínimo) aplicada en contextos reales de comunicación. Los actos de habla de los diálogos cotidianos constituyen el marco de la interacción terapéutica bajo la forma de "juegos terapéuticos de lenguaje" ${ }^{22}$. Como describen Pulvermüller et al. ${ }^{19}$, el material del juego es una baraja de cartas con imágenes de objetos o acciones, existiendo dos copias de cada una de estas imágenes; las cartas están estratégicamente diseñadas para adaptarse a distintos niveles de dificultad y de objetivos terapéuticos. La terapia se realiza en un grupo de unos 3 o 4 pacientes, que se encontrarán sentados en una mesa separada por tabiques, de forma que cada uno vea sus propias cartas, pero no las del resto de los compañeros; estos tabiques también impiden la visibilidad de los gestos o señales realizados inconscientemente. Por turnos, cada participante debe elegir una carta y solicitar a uno de sus compañeros mediante palabras u oraciones la pareja de la carta seleccionada, mientras que el compañero deberá responder a la petición de la misma forma. Este protocolo de interacción va evolucionando a lo largo de la intervención, añadiendo normas y restricciones que aumentan la dificultad del juego.

La terapia nació con el objetivo de desafiar las investigaciones que afirmaban que la recuperación de las funciones lingüísticas en afásicos crónicos (más de un año) era poco 
probable ${ }^{19}$. Partieron de los estudios neurocientíficos de Edward Taub y sus colaboradores, creadores de la "terapia de movimiento restringido", que apostaban por la rehabilitación de la movilidad perdida de una extremidad a causa de un ACV mediante la restricción del uso de la extremidad sana, al tiempo que se entrenaba de forma intensiva la afectada. Pulvermüller et al. ${ }^{19}$ extrapolaron estos supuestos a la recuperación de las funciones lingüísticas, diseñando una terapia centrada en la función perdida, restringiendo cualquier otro medio de comunicación. Esta perspectiva restrictiva o focalizadora se fundamenta en la teoría de que los pacientes afásicos aprenden a no usar la función perdida, ya que esta les produce frustración, sustituyéndola por otras formas de comunicación más accesibles (gestos, dibujos, etc.). A su vez, la práctica debe ser intensiva o masiva; el entorno terapéutico es óptimo para el establecimiento de nuevos vínculos neuronales y el aprendizaje, por lo que una práctica diaria e intensiva conseguiría un fortalecimiento cerebral más duradero y eficaz, sobre todo en un paciente que ya padece unos síntomas crónicos. Finalmente, como se ha comentado, la CIAT es una terapia comunicativa basada en la pragmática y la interacción social. Este enfoque radica en la noción de que el procesamiento del lenguaje a nivel cerebral no se corresponde con sistemas de procesamiento encapsulados en el área perisilviana, como defienden las teorías modulares, sino que también participan unas áreas adicionales relacionadas con los procesos de acción o motores. Este vínculo cortical entre el procesamiento motor y lingüístico justifica la importancia de enmarcar la terapia en contextos de acción relevantes para la vida cotidiana del paciente. En definitiva, la CIAT se sustenta sobre tres principios básicos: principio de restricción, de intensidad y de relevancia ${ }^{21,22}$.

Existen multitud de revisiones de esta terapia entre la comunidad científica. La mayoría de ellas concluye que la CIAT es una terapia con potencial que ha demostrado su éxito en pacientes con afasia crónica, pero que precisa investigaciones adicionales para concretar diversos aspectos ${ }^{23,24}$. Por ello, la terapia continúa en evolución. Se han añadido otros juegos y actividades y se ha perfilado el procedimiento, de forma que sea más adaptable a las características individuales de cada paciente; recientemente, se ha adoptado una nueva denominación para referirse a este grupo más complejo y renovado de procedimientos ecológicos e intensivos, Intensive Language-Action Therapy (ILAT) ${ }^{22}$, aunque las designaciones CIAT e ILAT continúan empleándose indistintamente. También se ha llevado a cabo la adaptación de la terapia al español en el año 2014 por parte del investigador Marcelo Berthier 
y sus colaboradores ${ }^{25}$, con el nombre de Rehabilitación Grupal Intensiva de la Afasia (REGIA), que constituye la primera comercialización de la técnica, en la que se han ampliado los objetivos y materiales de la terapia original. Además, se están llevando a cabo regularmente investigaciones sobre las bases cerebrales de los diferentes tipos de actos comunicativos, en los que monitorizan a los participantes mediante resonancia magnética funcional mientras visualizan determinados vídeos o ejecutan algunas tareas lingüísticas ${ }^{26}$. Por otro lado, las tendencias más recientes tienden a inclinarse hacia la combinación de la ILAT con otros tratamientos como la estimulación eléctrica transcraneal o fármacos, concretamente con memantina, pues parece arrojar mejores resultados en los pacientes que la terapia logopédica por sí sola 27 .

A raíz de la popularidad que han adquirido las terapias del grupo ILAT, la comunidad científica comenzó a centrar su interés en el factor intensidad de la intervención logopédica en pacientes afásicos. Algunos autores intentan determinar la intensidad óptima de la terapia; Bhogal et al. ${ }^{28}$ comentan que la intensidad mínima estimada sería de 5 a 10 horas semanales para asegurar un progreso significativo. Otras publicaciones se han centrado en la experimentación de forma intensiva con tratamientos tradicionales para afasia, cuando en origen no se plantearon como intensivas, tratando de obtener alguna conclusión esclarecedora.

Por otro lado, también han surgido otros programas de carácter intensivo, entre los que destacan los denominados Intensive Comprehensive Aphasia Programs (ICAP), programas que abarcan otras áreas además del lenguaje y la comunicación, como son la socialización, los factores psicológico-personales o el entorno del paciente ${ }^{29}$; y la Multi-modality Aphasia Therapy (M-MAT), terapia de carácter social que aboga por el empleo de otras modalidades comunicativas como medio para rehabilitar el habla, sin restricciones, a diferencia de la $\mathrm{CIAT}^{30}$.

En cualquier caso, las revisiones sistemáticas más recientes declaran que la intensidad de la terapia parece ser un componente determinante para el éxito de la misma, aunque la heterogeneidad de las publicaciones complica la obtención de conclusiones certeras $^{9,16}$. El objetivo de este trabajo es analizar este entramado de investigaciones acerca de las terapias intensivas y tratar de actualizar y organizar los hallazgos existentes. 


\section{OBJETIVOS}

La meta principal de este trabajo es actualizar los conceptos y evidencias sobre la intervención logopédica de alta intensidad en pacientes con afectación del lenguaje por DCA o afasia mediante una revisión sistemática. A partir de ello, se han propuesto los siguientes objetivos:

1) Comprobar la eficacia y los beneficios de la intervención logopédica de carácter intensivo en personas con afasia.

2) Determinar las diferencias existentes en las investigaciones con respecto a la dosis de la terapia intensiva en personas con afasia.

3) Analizar la influencia de las características de los pacientes y de la afasia en la eficacia del tratamiento intensivo.

4) Descubrir las metodologías y programas más utilizados en la intervención logopédica intensiva de personas con afasia. 


\section{METODOLOGÍA}

Entre los meses de febrero y junio de 2020 se ha realizado una revisión bibliográfica acerca de la intervención logopédica intensiva en pacientes con afasia, empleando las normas de citación del estilo Vancouver. Se han seleccionado un total de 59 documentos científicos, de los cuales 50 son artículos de revista, 6 libros o manuales y 3 publicaciones online de asociaciones y federaciones. El 85 \% del total de documentos revisados están escritos en inglés y el $15 \%$ en español. Los motores de búsqueda empleados han sido los siguientes: Pubmed, Cochrane, Google académico, SciElo, Elsevier, Reseacrh Gate, Taylor and Francis y las bases de datos y libros electrónicos suscritos por la Biblioteca de la Universidad de Valladolid; además, se han examinado las referencias bibliográficas de los documentos para identificar otros artículos adecuados. Se han empleado las siguientes palabras para la búsqueda: "afasia", "aphasia”, "afasia logopedia", "aphasia speech therapy", "afasia terapia intensiva”, "aphasia intensive therapy", "CIAT", "ILAT" y "REGIA". También se ha buscado a partir de los nombres de algunos investigadores, concretamente Friedmann Pulvermüller y Marcelo Luis Berthier.

El proceso de búsqueda y selección se realizó en dos fases. La primera de ellas tenía el objetivo de recopilar información general sobre la intervención logopédica en afasias y las terapias intensivas. Por ello, el único filtro aplicado fue la fecha de publicación posterior o igual al año 2005, salvo alguna excepción justificada por la relevancia histórica del artículo o del autor. Se seleccionaron 47 documentos en total. Posteriormente, se determinaron los criterios de selección de los ensayos clínicos sobre los que se realizaría la revisión sistemática reflejada en los resultados, teniendo en cuenta los objetivos propuestos. Los criterios de inclusión establecidos fueron: (a) ensayo clínico que aplicase una terapia logopédica intensiva en pacientes con afasia; y (b) fecha de publicación posterior al año 2010. Los criterios de exclusión se establecieron en base a las directrices de la Agencia de Evaluación de Tecnología e Investigación Médica de Cataluña ${ }^{31}$, descartando las investigaciones con un nivel de evidencia inferior, concretamente los estudios de caso único. De los 47 artículos revisados, únicamente 10 cumplían estos criterios. Por ello, se realizó una segunda búsqueda bibliográfica más exhaustiva. Finalmente, se recopilaron 59 documentos científicos, de los cuales 22 eran ensayos clínicos que cumplían los criterios establecidos, y el resto se utilizaron para otros epígrafes del trabajo. 


\section{RESULTADOS}

Se han revisado 59 publicaciones científicas, de las cuales 22 son ensayos clínicos (EC) sobre los que se ha realizado una revisión sistemática. En la Tabla 1 se presentan las características de los 22 artículos ordenados por año de publicación. Todos aplican una intervención logopédica de carácter intensivo en pacientes con afasia y comprueban su eficacia atendiendo a diversos objetivos y diseños de investigación.

La Tabla 1 se ha organizado en 8 columnas. En primer lugar, se refleja el autor, el año y el tipo de diseño del artículo. A continuación, se describe el objetivo de la investigación. En tercer lugar, se dispone la información referente a la muestra del estudio: el número total de pacientes (N), el diagnóstico (tipo de afasia, grado y etiología) y el tiempo transcurrido desde el DCA hasta el comienzo del estudio. No se han incluido las variables sexo y edad porque su influencia en la eficacia de la terapia no ha sido analizada con profundidad en ninguno de los estudios. Posteriormente, se describe la intervención logopédica aplicada en los pacientes o grupos de pacientes, así como la intensidad y duración de la misma. Finalmente, se muestra una síntesis de los resultados y conclusiones de cada investigación, omitiendo aquellos que se desvían de los objetivos propuestos en este trabajo de fin de grado.

La información incluida en las tablas refleja fielmente lo descrito en los artículos revisados, pero no todos los estudios detallan la información con el mismo formato ni con el mismo nivel de profundidad. Por ello, en la tabla puede no haber una estricta homogeneidad en la descripción de las características de cada investigación; esto sucede especialmente en el tiempo desde el DCA y en la intensidad y duración de la intervención logopédica.

En relación a la descripción de la intervención logopédica, en la mayoría de estudios se emplean programas terapéuticos específicos. En la tabla de resultados se indicará el nombre o las siglas del programa en cuestión y en el Anexo II se describirán brevemente los mismos. 
Tabla 1: Resultados de la revisión sistemática.

\begin{tabular}{|c|c|c|c|c|c|c|c|}
\hline \multirow{2}{*}{$\begin{array}{l}\text { Artículo } \\
\text { (autor/es, año y } \\
\text { tipo de estudio) }\end{array}$} & \multirow[b]{2}{*}{ Objetivos } & \multicolumn{3}{|c|}{ Pacientes } & \multicolumn{2}{|c|}{ Intervención logopédica } & \multirow[b]{2}{*}{ Resultados y conclusiones } \\
\hline & & $\mathbf{N}$ & Diagnóstico & $\begin{array}{l}\text { Tiempo } \\
\text { DCA }\end{array}$ & Descripción & $\begin{array}{c}\text { Frecuencia y } \\
\text { duración }\end{array}$ & \\
\hline $\begin{array}{c}\text { Laska et al. }{ }^{32} \\
\mathbf{2 0 1 1} \\
\text { EC con grupo } \\
\text { control, aleatorio, } \\
\text { con evaluación } \\
\text { ciega. }\end{array}$ & $\begin{array}{l}\text { Evaluar la eficacia } \\
\text { del tto logopédico } \\
\text { temprano y } \\
\text { moderadamente } \\
\text { intensivo en } \\
\text { pacientes afásicos. }\end{array}$ & 123 & $\begin{array}{c}\text { Afasia de } \\
\text { cualquier tipo } \\
\text { y grado, por } \\
\text { ACV } \\
\text { isquémico. }\end{array}$ & $\begin{array}{l}2 \text { días } \\
\text { (etapa } \\
\text { aguda) }\end{array}$ & $\begin{array}{l}\text { GE: terapia LET. } \\
\text { GC: sin tto. }\end{array}$ & $\begin{array}{c}\text { GE: sesiones de } \\
45 \text { minutos, } 5 \\
\text { días/semana, } 3 \\
\text { semanas. } 10- \\
\text { 11'5h en total. } \\
\text { GC: - }\end{array}$ & $\begin{array}{l}\text { - De forma general GE no obtuvo } \\
\text { mejoras significativas con respecto } \\
\text { a GC; no puede recomendarse LET } \\
\text { intensivo en pacientes agudos. } \\
\text { - Los factores más influyentes en la } \\
\text { mejora fueron el grado inicial de la } \\
\text { afasia y la gravedad del ACV. } \\
\text { - Los pacientes con afasia fluente del } \\
\text { GE obtuvieron mejores resultados. }\end{array}$ \\
\hline $\begin{array}{c}\text { Godecke et al. }^{33} \\
2012 \\
\text { EC con grupo } \\
\text { control, aleatorio, } \\
\text { con evaluación } \\
\text { ciega. }\end{array}$ & $\begin{array}{l}\text { Comprobar si el tto } \\
\text { logopédico } \\
\text { intensivo es más } \\
\text { eficaz que los } \\
\text { cuidados } \\
\text { habituales } \\
\text { hospitalarios en la } \\
\text { etapa aguda de } \\
\text { pacientes afásicos. }\end{array}$ & 59 & $\begin{array}{c}\text { Afasia no } \\
\text { fluente o } \\
\text { global, grado } \\
\text { medio-severo, } \\
\text { por ACV. }\end{array}$ & $\begin{array}{l}\text { Menos de } \\
5 \text { días } \\
\text { (etapa } \\
\text { aguda) }\end{array}$ & $\begin{array}{l}\text { GE: tto individual } \\
\text { centrado en el déficit. } \\
\text { Combina diferentes } \\
\text { terapias: BOX, Mapping } \\
\text { therapy, SFA y tareas de } \\
\text { descripción de } \\
\text { imágenes. } \\
\text { GC: cuidados } \\
\text { hospitalarios usuales } \\
\text { (85\% ningún tto). }\end{array}$ & $\begin{array}{l}\text { GE: sesiones } 30- \\
80 \text { minutos, } 5 \\
\text { días/ semana, } 4 \\
\text { semanas. } 10- \\
27 \mathrm{~h} \text { en total. } \\
\text { GC: se estiman } \\
14 \text { minutos/ } \\
\text { semana. }\end{array}$ & $\begin{array}{l}\text { - Los resultados del GE fueron } \\
\text { significativamente superiores que } \\
\text { los del GC tras } 4 \text { semanas. } \\
\text { - La intervención logopédica } \\
\text { intensiva temprana favorece la } \\
\text { restitución de la función perdida. } \\
\text { - La dosis óptima de tto intensivo } \\
\text { debe continuar investigándose, } \\
\text { pero esta parece que no debe ser } \\
\text { inferior a } 45 \text { minutos al día. }\end{array}$ \\
\hline
\end{tabular}

Abreviaturas: $\mathbf{N}=$ número de pacientes; $\mathbf{D C A}=$ daño cerebral adquirido; tto = tratamiento; $\mathbf{h}=$ hora/s; $\mathbf{A C V}=$ accidente cerebrovascular; $\mathbf{G E}=$ grupo experimental; $\mathbf{G C}$ = grupo control; LET = Language Enrichment Therapy; $\mathbf{B O X}=$ Lexical Semantic Therapy; SFA = Semantic Feature Analysis. 
Tabla 1: Resultados de la revisión sistemática (continuación).

\begin{tabular}{|c|c|c|c|c|c|c|c|}
\hline \multirow{2}{*}{$\begin{array}{c}\text { Artículo } \\
\text { (autor/es, año y } \\
\text { tipo de estudio) }\end{array}$} & \multirow[b]{2}{*}{ Objetivos } & \multicolumn{3}{|c|}{ Pacientes } & \multicolumn{2}{|c|}{ Intervención logopédica } & \multirow[b]{2}{*}{ Resultados y conclusiones } \\
\hline & & $\mathbf{N}$ & Diagnóstico & $\begin{array}{l}\text { Tiempo } \\
\text { DCA }\end{array}$ & Descripción & $\begin{array}{l}\text { Frecuencia y } \\
\text { duración }\end{array}$ & \\
\hline $\begin{array}{l}\text { Pavão et al. }{ }^{34} \\
2013 \\
\text { EC de grupos } \\
\text { paralelos, } \\
\text { aleatorio, ciego. }\end{array}$ & $\begin{array}{l}\text { Comparar el efecto } \\
\text { de } 100 \mathrm{~h} \text { de terapia } \\
\text { aplicadas en un } \\
\text { régimen intensivo y } \\
\text { en un régimen } \\
\text { regular. }\end{array}$ & 30 & $\begin{array}{l}\text { Afasia de } \\
\text { cualquier } \\
\text { tipo, grado } \\
\text { medio- } \\
\text { severo por } \\
\text { ACV en la } \\
\text { ACM. }\end{array}$ & $\begin{array}{l}\text { Menos de } \\
3 \text { meses } \\
\text { (etapa sub- } \\
\text { aguda) }\end{array}$ & $\begin{array}{c}\text { Sesiones individuales } \\
\text { con terapia MSA. }\end{array}$ & $\begin{array}{l}\text { G1: sesiones } 2 \text { horas, } \\
5 \text { días/semana, } 10 \\
\text { semanas ( } 100 \mathrm{~h}) \text {. } \\
\text { G2: sesiones } 2 \text { horas, } \\
1 \text { día/semana, } 50 \\
\text { semanas (100h). }\end{array}$ & $\begin{array}{c}\text { No se han encontrado diferencias } \\
\text { estadísticamente significativas } \\
\text { entre ambos grupos ( } 9 \text { pacientes } \\
\text { de cada grupo mejoraron } \\
\text { significativamente), pero se } \\
\text { observa una tendencia a resultados } \\
\text { más favorables en G1 (intensivo). }\end{array}$ \\
\hline $\begin{array}{l}\text { Rose et al. }{ }^{35} 2013 \\
\text { EC de grupos } \\
\text { cruzados, } \\
\text { aleatorio. }\end{array}$ & $\begin{array}{l}\text { Comparar la } \\
\text { eficacia de M-MAT } \\
\text { y CIAT en pacientes } \\
\text { con afasia crónica, } \\
\text { y explorar las } \\
\text { variables que } \\
\text { influyen en la } \\
\text { posible respuesta } \\
\text { diferente al } \\
\text { tratamiento. }\end{array}$ & 11 & $\begin{array}{l}\text { Afasia de } \\
\text { Broca, } \\
\text { anómica y } \\
\text { conducción; } \\
\text { grado } \\
\text { medio- } \\
\text { severo; por } \\
\text { ACV. }\end{array}$ & $\begin{array}{l}\text { Entre } 17 \text { y } \\
88 \text { meses } \\
\text { (etapa } \\
\text { crónica) }\end{array}$ & $\begin{array}{l}\text { Se aplican de forma } \\
\text { cruzada dos terapias } \\
\text { intensivas grupales: } \\
\text { CIAT y M-MAT. } \\
\text { G1 recibe CIAT } \\
\text { primero, y después M- } \\
\text { CHAT; G2, al contrario. }\end{array}$ & $\begin{array}{l}\text { Sesiones 3'25h, } 4 \\
\text { días/semana, } 2 \\
\text { semanas. } \\
\text { 32h cada tto, } 64 \text { en } \\
\text { total. }\end{array}$ & $\begin{array}{l}\text { - Ambas terapias fueron eficaces } \\
\text { similarmente y en el seguimiento. } \\
\text { - Seis pacientes mostraron } \\
\text { preferencia por M-MAT. } \\
\text { - No se ha detectado ningún factor } \\
\text { que predijera significativamente } \\
\text { la respuesta al tto. } \\
\text { - Los sustantivos respondían mejor } \\
\text { al tto que los verbos; las terapias } \\
\text { deben incidir más en los verbos. }\end{array}$ \\
\hline $\begin{array}{l}\text { Godecke et al. }^{36} \\
\qquad 2014 \\
\text { EC con grupo } \\
\text { control histórico y } \\
\text { evaluación ciega. }\end{array}$ & $\begin{array}{l}\text { Demostrar que el } \\
\text { tto logopédico muy } \\
\text { temprano, } \\
\text { estandarizado e } \\
\text { intensivo es eficaz } \\
\text { en pacientes con } \\
\text { afasia. }\end{array}$ & 47 & $\begin{array}{l}\text { Afasia de } \\
\text { cualquier } \\
\text { tipo y grado } \\
\text { por ACV. }\end{array}$ & $\begin{array}{l}\text { Menos de } \\
14 \text { días } \\
\text { (etapa } \\
\text { aguda) }\end{array}$ & $\begin{array}{l}\text { GE: tto grupal con } \\
\text { CIAT y tto individual } \\
\text { que combina BOX, } \\
\text { Mapping therapy, SFA } \\
\text { y NT. } \\
\text { GC: grupo control de } \\
\text { Godecke et } \mathrm{al}^{33} \text {. }\end{array}$ & $\begin{array}{l}\text { GE: sesiones } 45-60 \\
\text { minutos, } 5 \\
\text { días/semana, } 4 \\
\text { semanas (15-20h en } \\
\quad \text { total). } \\
\text { GC: se estiman } 14 \\
\text { minutos/semana. }\end{array}$ & $\begin{array}{l}\text { - El tto logopédico temprano, } \\
\text { intensivo y centrado en el déficit } \\
\text { dio buenos resultados tanto a } \\
\text { corto plazo como en el } \\
\text { seguimiento ( } 6 \text { meses). } \\
\text { - Los pacientes con afasia aguda } \\
\text { toleraron el tto. }\end{array}$ \\
\hline
\end{tabular}

Abreviaturas: $\mathbf{N}=$ número de pacientes; $\mathbf{D C A}=$ daño cerebral adquirido; $\mathbf{t t o}=$ tratamiento; $\mathbf{h}=$ hora $/ \mathrm{s} ; \mathbf{A C V}=$ accidente cerebrovascular; $\mathbf{G E}=$ grupo experimental;

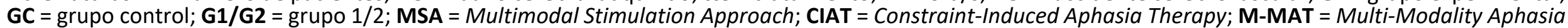
Therapy; BOX = Lexical Semantic Therapy; SFA = Semantic Feature Analysis; NT = Naming Therapy. 
Tabla 1: Resultados de la revisión sistemática (continuación).

\begin{tabular}{|c|c|c|c|c|c|c|c|}
\hline \multirow{2}{*}{$\begin{array}{l}\text { Artículo } \\
\text { (autor/es, año y } \\
\text { tipo de estudio) }\end{array}$} & \multirow[b]{2}{*}{ Objetivos } & \multicolumn{3}{|c|}{ Pacientes } & \multicolumn{2}{|c|}{ Intervención logopédica } & \multirow[b]{2}{*}{ Resultados y conclusiones } \\
\hline & & $\mathbf{N}$ & Diagnóstico & $\begin{array}{c}\text { Tiempo } \\
\text { DCA }\end{array}$ & Descripción & $\begin{array}{c}\text { Frecuencia y } \\
\text { duración }\end{array}$ & \\
\hline $\begin{array}{l}\text { Sickert et al. } \\
\qquad 2014 . \\
\text { EC de grupos } \\
\text { paralelos, } \\
\text { aleatorio, con } \\
\text { evaluación ciega. }\end{array}$ & $\begin{array}{l}\text { Evaluar la vialidad } \\
\text { de la CIAT } \\
\text { modificada para } \\
\text { afásicos subagudos } \\
\text { y examinar la } \\
\text { eficacia de la CIAT } \\
\text { versus el tto } \\
\text { estándar intensivo. }\end{array}$ & 100 & $\begin{array}{c}\text { Afasia de } \\
\text { cualquier tipo, } \\
\text { grado leve- } \\
\text { severo, por } \\
\text { ACV. }\end{array}$ & $\begin{array}{l}\text { Entre } 1 \text { y } \\
4 \text { meses } \\
\text { (etapa } \\
\text { sub- } \\
\text { aguda) }\end{array}$ & $\begin{array}{l}\text { G1: CIAT, incluyendo } \\
\text { escritura. } \\
\text { G2: tto convencional } \\
\text { (sin restricciones) } \\
\text { centrado en el déficit } \\
\text { con ejercicios } \\
\text { variados. }\end{array}$ & $\begin{array}{c}\text { En ambos } \\
\text { grupos sesiones } \\
\text { de } 2 \mathrm{~h} \text { durante, } 5 \\
\text { días/semana, } 2 \\
\text { semanas. }\end{array}$ & $\begin{array}{l}\text { - Se demuestra la viabilidad de las dos } \\
\text { terapias por igual en la etapa } \\
\text { subaguda. } \\
\text { - Los resultados se mantuvieron } \\
\text { estables en el seguimiento ( } 1 \text { año). } \\
\text { - Las mejoras no se relacionaron con la } \\
\text { edad, el sexo o el tipo de afasia. } \\
\text { - Ningún paciente detuvo la terapia. }\end{array}$ \\
\hline $\begin{array}{l}\text { Van der Meulen } \\
\text { et al. }{ }^{38} \mathbf{2 0 1 4 .} \\
\text { EC de grupos } \\
\text { paralelos, } \\
\text { aleatorio, con } \\
\text { evaluación ciega. }\end{array}$ & $\begin{array}{l}\text { Evaluar la eficacia } \\
\text { de la MIT como } \\
\text { terapia de } \\
\text { producción de } \\
\text { lenguaje para la } \\
\text { afasia severa no } \\
\text { fluida en la fase } \\
\text { subaguda. }\end{array}$ & 27 & $\begin{array}{l}\text { Afasia no } \\
\text { fluente, } \\
\text { severa, por } \\
\text { ACV. }\end{array}$ & $\begin{array}{l}\text { 2-3 meses } \\
\text { (etapa } \\
\text { sub- } \\
\text { aguda) }\end{array}$ & $\begin{array}{l}\text { G1: MIT. } \\
\text { G2: tto centrado en } \\
\text { escritura, } \\
\text { comprensión oral y } \\
\text { comunicación no } \\
\text { verbal; no se hizo } \\
\text { hincapié en la } \\
\text { producción oral. }\end{array}$ & $\begin{array}{l}\text { En ambos } \\
\text { grupos, 3- } \\
\text { 5h/semana de } \\
\text { terapia durante } \\
6 \text { semanas y } \\
\text { tareas para } \\
\text { casa. }\end{array}$ & $\begin{array}{l}\text { - Los resultados del G1 fueron } \\
\text { significativamente superiores a los del } \\
\text { G2, especialmente en repetición y } \\
\text { comunicación verbal. } \\
\text { - El tto intensivo centrado en la } \\
\text { producción verbal fue viable en la } \\
\text { etapa subaguda. } \\
\text { - Se sugiere que una intensidad mayor } \\
\text { probablemente produciría mejores } \\
\text { resultados. }\end{array}$ \\
\hline $\begin{array}{l}\text { Wilssens et al. }{ }^{39} \\
\qquad \begin{array}{c}2015 \\
\text { EC de grupos } \\
\text { paralelos, } \\
\text { aleatorio. }\end{array}\end{array}$ & $\begin{array}{l}\text { Comprobar la } \\
\text { eficacia de las } \\
\text { terapias CIAT y BOX } \\
\text { aplicadas de forma } \\
\text { intensiva en } \\
\text { pacientes con } \\
\text { afasia fluente. }\end{array}$ & 9 & $\begin{array}{l}\text { Afasia fluente } \\
\text { (Wernicke o } \\
\text { transcortical } \\
\text { sensorial) } \\
\text { moderada, por } \\
\text { ACV. }\end{array}$ & $\begin{array}{l}\text { Más de } \\
17 \text { meses } \\
\text { (etapa } \\
\text { crónica) }\end{array}$ & $\begin{array}{l}\text { G1: CIAT. } \\
\text { G2: terapia léxica- } \\
\text { semántica basada en } \\
\text { la práctica usando el } \\
\text { programa BOX. } \\
\text { Combina individual y } \\
\text { grupal. }\end{array}$ & $\begin{array}{c}\text { En ambos } \\
\text { grupos sesiones } \\
\text { de 2-3h durante } \\
\text { 9-10 días } \\
\text { laborales } \\
\text { consecutivos. }\end{array}$ & $\begin{array}{l}\text { - Ambos grupos han obtenido mejoras } \\
\text { significativas; BOX fue más eficaz en } \\
\text { semántica y comprensión; CIAT en } \\
\text { producción del lenguaje (repetición, } \\
\text { denominación y fonología). } \\
\text { - Tanto la intensidad como el enfoque } \\
\text { del tto influyen en los resultados. }\end{array}$ \\
\hline
\end{tabular}

Abreviaturas: $\mathbf{N}=$ número de pacientes; $\mathbf{D C A}=$ daño cerebral adquirido; $\mathbf{t t o}=$ tratamiento; $\mathbf{h}=$ hora/s; $\mathbf{A C V}=$ accidente cerebrovascular; $\mathbf{G E}=$ grupo experimental; GC = grupo control; G1/G2 = grupo 1/2; CIAT = Constraint-Induced Aphasia Therapy; MIT = Melodic Intonation Therapy; BOX = Lexical Semantic Therapy . 
Tabla 1: Resultados de la revisión sistemática (continuación).

\begin{tabular}{|c|c|c|c|c|c|c|c|}
\hline \multirow{2}{*}{$\begin{array}{l}\text { Artículo (autor/es, } \\
\text { año y tipo de } \\
\text { estudio) }\end{array}$} & \multirow[b]{2}{*}{ Objetivos } & \multicolumn{3}{|c|}{ Pacientes } & \multicolumn{2}{|c|}{ Intervención logopédica } & \multirow[b]{2}{*}{ Resultados y conclusiones } \\
\hline & & $\mathbf{N}$ & Diagnóstico & $\begin{array}{c}\text { Tiempo } \\
\text { DCA }\end{array}$ & Descripción & $\begin{array}{c}\text { Frecuencia y } \\
\text { duración }\end{array}$ & \\
\hline $\begin{array}{l}\text { Szaflarski et al. }{ }^{40} \\
\qquad 2015 \\
\text { EC con grupo } \\
\text { control, aleatorio, } \\
\text { ciego. }\end{array}$ & $\begin{array}{l}\text { Estimar la eficacia } \\
\text { de la CIAT en } \\
\text { comparación con } \\
\text { la ausencia de tto } \\
\text { en pacientes con } \\
\text { afasia crónica. }\end{array}$ & 24 & $\begin{array}{l}\text { Afasia de } \\
\text { cualquier tipo, } \\
\text { grado medio- } \\
\text { severo, por } \\
\text { ACV isquémico } \\
\text { en la ACM. }\end{array}$ & $\begin{array}{l}\text { Más de } \\
\text { un año } \\
\text { (etapa } \\
\text { crónica) }\end{array}$ & $\begin{array}{c}\text { GE: CIAT con objetivos } \\
\text { individualizados y } \\
\text { jerarquizados. } \\
\text { GC: no tto. }\end{array}$ & $\begin{array}{l}\text { GE: sesiones } 4 \mathrm{~h}, \\
5 \text { días/semana, } 2 \\
\text { semanas. } \\
\text { GC: - }\end{array}$ & $\begin{array}{l}\text { - Se observaron mejoras modestas en el } \\
\text { GE con respecto al GC; la diferencia } \\
\text { más significativa se encontró a nivel } \\
\text { pragmático-comunicativo. } \\
\text { - El potencial de la CIAT debe continuar } \\
\text { investigándose. }\end{array}$ \\
\hline $\begin{array}{l}\text { Ciccone et al. }{ }^{41} \\
\qquad 2015 \\
\text { EC de grupos } \\
\text { paralelos, } \\
\text { aleatorio, con } \\
\text { evaluación ciega. }\end{array}$ & $\begin{array}{l}\text { Comparar la } \\
\text { eficacia de la CIAT } \\
\text { y de un tto } \\
\text { intensivo } \\
\text { individual } \\
\text { centrado en el } \\
\text { déficit en afásicos } \\
\text { agudos. }\end{array}$ & 20 & $\begin{array}{l}\text { Afasia de } \\
\text { cualquier tipo, } \\
\text { grado medio- } \\
\text { severo, por } \\
\text { ACV }\end{array}$ & $\begin{array}{l}\text { Menos } \\
\text { de } 10 \\
\text { días } \\
\text { (etapa } \\
\text { aguda) }\end{array}$ & $\begin{array}{l}\text { G1: CIAT. } \\
\text { G2: tto individualizado } \\
\text { centrado en el déficit que } \\
\text { combina BOX, Mapping } \\
\text { therapy, SFA, Naming } \\
\text { Therapy y tto fonológico. }\end{array}$ & $\begin{array}{l}\text { En ambos grupos } \\
\text { sesiones de } 45- \\
60 \text { minutos, } 5 \\
\text { días/semana, } \\
\text { durante } 4-5 \\
\text { semanas. } 20 \\
\text { sesiones en total } \\
\text { (15-20h). }\end{array}$ & $\begin{array}{l}\text { - Tanto CIAT como el tto individual } \\
\text { fueron eficaces, manteniéndose los } \\
\text { resultados tras } 12 \text { semanas. } \\
\text { - No hubo diferencias significativas } \\
\text { entre los dos ttos, aunque G1 mostró } \\
\text { mejores resultados a nivel de discurso. } \\
\text { - La terapia moderadamente intensiva } \\
\text { parece ser adecuada en la etapa aguda } \\
\text { de la afasia. }\end{array}$ \\
\hline $\begin{array}{l}\text { Dignam et al. }{ }^{42} \\
\qquad 2015 \\
\text { EC de grupos } \\
\text { paralelos, no } \\
\text { aleatorio. }\end{array}$ & $\begin{array}{l}\text { Comparar la } \\
\text { eficacia de un } \\
\text { programa ICAP } \\
\text { aplicado de forma } \\
\text { intensiva versus } \\
\text { distribuida. }\end{array}$ & 32 & $\begin{array}{l}\text { Afasia de } \\
\text { cualquier tipo y } \\
\text { grado por ACV. }\end{array}$ & $\begin{array}{l}\text { Más de } \\
4 \text { meses } \\
\text { (etapa } \\
\text { crónica) }\end{array}$ & $\begin{array}{l}\text { G1 y G2 reciben un ICAP, } \\
\text { concretamente la LIFT, que } \\
\text { incluye: tto centrado en el } \\
\text { déficit (anomia), terapia } \\
\text { comunicativa-funcional, } \\
\text { entrenamiento con } \\
\text { programas informáticos y } \\
\text { sesiones grupales } \\
\text { informativas y de } \\
\text { asesoramiento. }\end{array}$ & $\begin{array}{l}\text { G1: sesiones de } \\
\text { 3-4h, } 5 \\
\text { días/semana, } 3 \\
\text { semanas. } 48 \mathrm{~h} \text { en } \\
\text { total. } \\
\text { G2: sesiones de } \\
\text { 1-2h, } 3-4 \\
\text { días/semana, } 8 \\
\text { semanas. } 48 \mathrm{~h} \text { en } \\
\text { total. }\end{array}$ & $\begin{array}{l}\text { - Ambos grupos mostraron mejoras } \\
\text { significativas a nivel lingüístico, } \\
\text { comunicativo y de calidad de vida. } \\
\text { - El G2 (tto distribuido) presentó } \\
\text { ganancias superiores que el G1 (tto } \\
\text { intensivo), además de resultar más } \\
\text { viable para los pacientes y para los } \\
\text { profesionales. }\end{array}$ \\
\hline
\end{tabular}

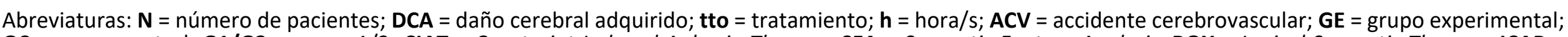

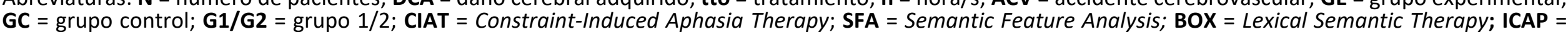
Intensive Comprehensive Aphasia Program; LIFT = Language Impairment and Functioning Therapy. 
Tabla 1: Resultados de la revisión sistemática (continuación).

\begin{tabular}{|c|c|c|c|c|c|c|c|}
\hline \multirow{2}{*}{$\begin{array}{c}\text { Artículo } \\
\text { (autor/es, año y } \\
\text { tipo de estudio) }\end{array}$} & \multirow[b]{2}{*}{ Objetivos } & \multicolumn{3}{|c|}{ Pacientes } & \multicolumn{2}{|c|}{ Intervención logopédica } & \multirow[b]{2}{*}{ Resultados y conclusiones } \\
\hline & & $\mathbf{N}$ & Diagnóstico & $\begin{array}{c}\text { Tiempo } \\
\text { DCA }\end{array}$ & Descripción & $\begin{array}{c}\text { Frecuencia y } \\
\text { duración }\end{array}$ & \\
\hline $\begin{array}{l}\text { Stahl et al. }{ }^{43} 2016 \\
\text { EC de grupos } \\
\text { cruzados, } \\
\text { aleatorio. }\end{array}$ & $\begin{array}{l}\text { Contrastar el } \\
\text { impacto de la } \\
\text { terapia intensiva } \\
\text { centrada en la } \\
\text { denominación con } \\
\text { la centrada en la } \\
\text { pragmática en } \\
\text { afásicos crónicos. }\end{array}$ & 18 & $\begin{array}{l}\text { Afasia no } \\
\text { fluente (Broca } \\
\text { o global), } \\
\text { grado medio- } \\
\text { severo; por } \\
\text { ACV, TCE o } \\
\text { encefalitis } \\
\text { viral. }\end{array}$ & $\begin{array}{l}\text { Más de } \\
\text { un año } \\
\text { (etapa } \\
\text { crónica) }\end{array}$ & $\begin{array}{l}\text { G1 y G2 reciben de } \\
\text { forma cruzada dos } \\
\text { terapias: ILAT y NT } \\
\text { intensiva. } \\
\text { G1 recibe ILAT primero, } \\
\text { y después NT; G2, al } \\
\text { contrario. }\end{array}$ & $\begin{array}{l}\text { - P1 y P3: } \\
\text { (periodos de } \\
\text { tto): sesiones } \\
\text { de 3'5h, } 6 \text { días } \\
\text { consecutivos. } \\
\text { 21h cada tto, } \\
\text { 42h en total. } \\
\text { - P2: } 6 \text { días sin } \\
\text { tto. }\end{array}$ & $\begin{array}{l}\text { - Se demuestra la mayor eficacia del } \\
\text { enfoque basado en la interacción } \\
\text { comunicativa (ILAT) con respecto a } \\
\text { las tareas de denominación en la } \\
\text { recuperación de las funciones } \\
\text { lingüísticas afectadas en pacientes } \\
\text { con afasia crónica. } \\
\text { - No se hallaron diferencias entre los } \\
\text { pacientes con afasia vascular y no } \\
\text { vascular; debe investigarse más. }\end{array}$ \\
\hline $\begin{array}{l}\text { Kurland et al. } \\
\qquad 2016 \\
\text { EC de grupos } \\
\text { paralelos, } \\
\text { aleatorio, con } \\
\text { evaluación ciega. }\end{array}$ & $\begin{array}{l}\text { Evaluar si el } \\
\text { principio de } \\
\text { restricción de la } \\
\text { ILAT es crítico para } \\
\text { el éxito de la } \\
\text { terapia, mediante } \\
\text { un estudio } \\
\text { comparativo de la } \\
\text { ILAT y la PACE. }\end{array}$ & 24 & $\begin{array}{l}\text { Afasia de } \\
\text { cualquier tipo, } \\
\text { grado medio- } \\
\text { severo, por } \\
\text { ACV. }\end{array}$ & $\begin{array}{c}\text { Entre } 6 \text { y } \\
142 \\
\text { meses } \\
\text { (etapa } \\
\text { crónica) }\end{array}$ & $\begin{array}{c}\text { Varios juegos } \\
\text { terapéuticos con una } \\
\text { baraja de } 40 \text { imágenes. } \\
\text { G1: ILAT, focaliza en el } \\
\text { lenguaje hablado. } \\
\text { G2: PACE, permite el uso } \\
\text { de alternativas al } \\
\text { lenguaje hablado. }\end{array}$ & $\begin{array}{l}\text { Sesiones de } 3 \mathrm{~h} \text {, } \\
5 \text { días/semana, } \\
2 \text { semanas. } 10 \\
\text { sesiones en } \\
\text { total. }\end{array}$ & $\begin{array}{l}\text { - Ambos grupos alcanzaron } \\
\text { beneficios notables en el lenguaje } \\
\text { oral, sin ser significativas las } \\
\text { diferencias entre los dos grupos. } \\
\text { - No puede concluirse si la restricción } \\
\text { es un factor crítico de la ILAT, pero } \\
\text { ciertamente se atisba cierta ventaja } \\
\text { en la generalización de los } \\
\text { aprendizajes en el G1. }\end{array}$ \\
\hline
\end{tabular}

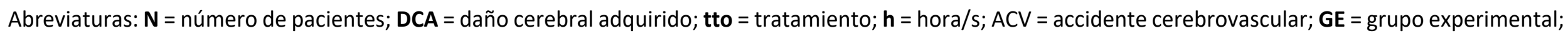

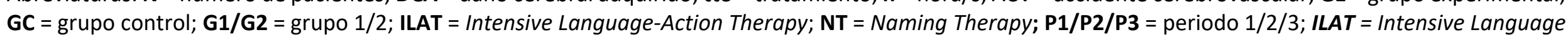
Aphasia Therapy; PACE = Promoting Aphasic Communicative Effectiveness. 
Tabla 1: Resultados de la revisión sistemática (continuación).

\begin{tabular}{|c|c|c|c|c|c|c|c|}
\hline \multirow{2}{*}{$\begin{array}{l}\text { Artículo } \\
\text { (autor/es, año y } \\
\text { tipo de estudio) }\end{array}$} & \multirow[b]{2}{*}{ Objetivos } & \multicolumn{3}{|c|}{ Pacientes } & \multicolumn{2}{|c|}{ Intervención logopédica } & \multirow[b]{2}{*}{ Resultados y conclusiones } \\
\hline & & $\mathbf{N}$ & Diagnóstico & $\begin{array}{c}\text { Tiempo } \\
\text { DCA }\end{array}$ & Descripción & $\begin{array}{c}\text { Frecuencia y } \\
\text { duración }\end{array}$ & \\
\hline $\begin{array}{l}\text { Mozeiko et al. }{ }^{45} \\
\qquad 2016 \\
\text { EC de línea base } \\
\text { múltiple, con } \\
\text { grupos } \\
\text { escalonados, no } \\
\text { aleatorio. }\end{array}$ & $\begin{array}{l}\text { Investigar el } \\
\text { efecto de la } \\
\text { intensidad de la } \\
\text { CIAT comparando } \\
\text { una dosis } \\
\text { intensiva con una } \\
\text { dosis más } \\
\text { distribuida. }\end{array}$ & 8 & $\begin{array}{l}\text { Afasia de } \\
\text { cualquier } \\
\text { tipo, grado } \\
\text { medio- } \\
\text { severo, por } \\
\text { ACV. }\end{array}$ & $\begin{array}{l}\text { Más de } \\
\text { un año } \\
\text { (etapa } \\
\text { crónica) }\end{array}$ & $\begin{array}{c}\text { Ambos grupos recibieron } \\
\text { un tratamiento idéntico de } \\
\text { tipo CIAT. }\end{array}$ & $\begin{array}{l}\text { G1: sesiones de } 3 \mathrm{~h}, \\
5 \text { días/semana, } 2 \\
\text { semanas. } 10 \\
\text { sesiones en total } \\
\text { (30h). } \\
\text { G2: sesiones de } 1 \mathrm{~h}, \\
3 \text { días/semana, } 10 \\
\text { semanas. } 30 \\
\text { sesiones en total } \\
\text { (30h). }\end{array}$ & $\begin{array}{l}\text { - Se observaron ganancias positivas } \\
\text { en todos los participantes en las } \\
\text { medidas de severidad de la afasia, } \\
\text { discurso y comunicación en la vida } \\
\text { cotidiana. } \\
\text { - G1 (dosis intensiva) presentó una } \\
\text { ligera ventaja tras el tto y en el } \\
\text { seguimiento ( } 1 \text { mes). }\end{array}$ \\
\hline $\begin{array}{l}\text { Hoover et al. }{ }^{46} \\
2016 \\
\text { EC de caso } \\
\text { múltiple, } \\
\text { controlado. }\end{array}$ & $\begin{array}{l}\text { Investigar los } \\
\text { beneficios del } \\
\text { habla, el lenguaje } \\
\text { y la calidad de } \\
\text { vida de un ICAP } \\
\text { en personas con } \\
\text { afasia crónica. }\end{array}$ & 27 & $\begin{array}{l}\text { Afasia de } \\
\text { cualquier } \\
\text { tipo, grado } \\
\text { medio- } \\
\text { severo, por } \\
\text { ACV. }\end{array}$ & $\begin{array}{l}\text { Más de } \\
6 \text { meses } \\
\text { (etapa } \\
\text { crónica) }\end{array}$ & $\begin{array}{c}\text { Tto interdisciplinar (ICAP): } \\
\text { logopedia, terapia } \\
\text { ocupacional, fisioterapia y } \\
\text { nutrición. } \\
\text { Logopedia: grupal } \\
\text { (expresión verbal } \\
\text { cotidiana), por parejas } \\
\text { (CIAT y PACE) e individual } \\
\text { (contenidos } \\
\text { individualizados). }\end{array}$ & $\begin{array}{l}\text { 6h diarias de tto } \\
\text { interdisciplinar. } \\
\text { Logopedia: } \\
\text { sesiones de } 3 \mathrm{~h}, 5 \\
\text { días/semana, } 4 \\
\text { semanas. } 62 \mathrm{~h} \text { en } \\
\text { total. }\end{array}$ & $\begin{array}{l}\text { Mejoras significativas y objetivas en } \\
\text { el lenguaje, comunicación y calidad } \\
\text { de vida de todos los pacientes. Los } \\
\text { resultados permanecieron estables } \\
\text { en el seguimiento ( } 3 \text { meses). }\end{array}$ \\
\hline
\end{tabular}

Abreviaturas: $\mathbf{N}=$ número de pacientes; $\mathbf{D C A}=$ daño cerebral adquirido; $\mathbf{t t o}=$ tratamiento; $\mathbf{h}=\mathrm{hora} / \mathrm{s} ; \mathbf{A C V}=$ accidente cerebrovascular; $\mathbf{G E}=$ grupo experimental; GC = grupo control; G1/G2 = grupo 1/2; CIAT = Constraint-Induced Aphasia Therapy PACE $=$ Promoting Aphasic Communicative Effectiveness. 
Tabla 1: Resultados de la revisión sistemática (continuación).

\begin{tabular}{|c|c|c|c|c|c|c|c|}
\hline \multirow{2}{*}{$\begin{array}{l}\text { Artículo } \\
\text { (autor/es, año y } \\
\text { tipo de estudio) }\end{array}$} & \multirow[b]{2}{*}{ Objetivos } & \multicolumn{3}{|c|}{ Pacientes } & \multicolumn{2}{|c|}{ Intervención logopédica } & \multirow[b]{2}{*}{ Resultados y conclusiones } \\
\hline & & $\mathbf{N}$ & Diagnóstico & $\begin{array}{c}\text { Tiempo } \\
\text { DCA }\end{array}$ & Descripción & $\begin{array}{c}\text { Frecuencia y } \\
\text { duración }\end{array}$ & \\
\hline $\begin{array}{l}\text { Mohr et al. }{ }^{47} \\
2017 \\
\text { EC de grupos } \\
\text { cruzados, } \\
\text { aleatorio, con } \\
\text { evaluación ciega. }\end{array}$ & $\begin{array}{l}\text { Determinar si el tto } \\
\text { logopédico } \\
\text { intensivo puede } \\
\text { reducir los } \\
\text { síntomas de } \\
\text { depresión en } \\
\text { pacientes con } \\
\text { afasia crónica, y } \\
\text { qué enfoque es } \\
\text { más beneficioso. }\end{array}$ & 18 & $\begin{array}{l}\text { Afasia no } \\
\text { fluente (Broca } \\
\text { o global), } \\
\text { grado medio- } \\
\text { severo; por } \\
\text { ACV, TCE o } \\
\text { encefalitis. } \\
\text { Ver muestra } \\
\text { de Stahl et } \\
\text { al. }{ }^{43}\end{array}$ & $\begin{array}{l}\text { Entre } 1 \text { y } \\
20 \text { años } \\
\text { (etapa } \\
\text { crónica) }\end{array}$ & $\begin{array}{l}\text { G1 y G2 reciben de } \\
\text { forma cruzada dos } \\
\text { terapias: ILAT y NT } \\
\text { intensiva. } \\
\text { G1 recibe ILAT primero, } \\
\text { y después NT; G2, al } \\
\text { contrario. }\end{array}$ & $\begin{array}{l}3 \text { periodos }(\mathrm{P}) \text { : } \\
\text { - } \mathrm{P} 1 \text { y } \mathrm{P} 3 \\
\text { (periodos de } \\
\text { tto): sesiones } \\
\text { de 3'5h, } 6 \text { días } \\
\text { consecutivos. } \\
\text { 21h cada tto, } \\
\text { 42h en total. } \\
\text { - P2: } 6 \text { días sin } \\
\text { tto. }\end{array}$ & $\begin{array}{l}\text { - La ILAT demuestra una disminución } \\
\text { significativa de los síntomas de la } \\
\text { depresión, al contrario que la NT. } \\
\text { Además, este efecto positivo } \\
\text { parece independiente de la mejora } \\
\text { del nivel lingüístico. } \\
\text { - La interacción social que sustenta la } \\
\text { ILAT, y que la diferencia de la NM, } \\
\text { pueden haber contribuido a } \\
\text { mejorar el estado de ánimo de los } \\
\text { pacientes. }\end{array}$ \\
\hline $\begin{array}{l}\text { Nouwens et al. }{ }^{48} \\
\qquad 2017 \\
\text { EC con grupo } \\
\text { control, aleatorio, } \\
\text { con evaluación } \\
\text { ciega. }\end{array}$ & $\begin{array}{c}\text { Estudiar si la } \\
\text { terapia intensiva y } \\
\text { temprana de } \\
\text { enfoque cognitivo- } \\
\text { lingüístico es eficaz } \\
\text { a corto y largo } \\
\text { plazo en pacientes } \\
\text { con afasia. }\end{array}$ & 152 & $\begin{array}{c}\text { Afasia de } \\
\text { cualquier tipo, } \\
\text { grado medio- } \\
\text { severo, por } \\
\text { ACV. }\end{array}$ & $\begin{array}{c}2 \\
\text { semanas } \\
\text { (etapa } \\
\text { aguda) }\end{array}$ & $\begin{array}{l}\text { GE: se utilizaron la } \\
\text { terapia BOX y/o el } \\
\text { programa FIKS. } \\
\text { GC: sin tto. }\end{array}$ & $\begin{array}{l}\text { GE: sesiones } 1 \mathrm{~h} \\
\text { mínimo, todos } \\
\text { los días, } 4 \\
\text { semanas. } 28 \mathrm{~h} \\
\text { en total. } \\
\text { GC: - }\end{array}$ & $\begin{array}{l}\text { - No hubo diferencias significativas } \\
\text { entre GE y GC. Sugieren que, en la } \\
\text { fase aguda, los logopedas se } \\
\text { centren en asesoramiento más que } \\
\text { en el déficit lingüístico. } \\
\text { - Menos del } 30 \% \text { del GE alcanzó las } \\
28 \text { h totales debido a cansancio o } \\
\text { problemas de salud; los ttos } \\
\text { intensivos en etapa temprana } \\
\text { tienen una viabilidad dudosa. }\end{array}$ \\
\hline
\end{tabular}

Abreviaturas: $\mathbf{N}=$ número de pacientes; $\mathbf{D C A}=$ daño cerebral adquirido; $\mathbf{t t o}=$ tratamiento; $\mathbf{h}=$ hora/s; $\mathbf{A C V}=$ accidente cerebrovascular; $\mathbf{G E}=$ grupo experimental; $\mathbf{G C}=$ grupo control; G1/G2 = grupo 1/2; ILAT = Intensive Language-Action Therapy; $\mathbf{N} \mathbf{T}=$ Naming Therapy; $\mathbf{P 1} / \mathbf{P 2} / \mathbf{P 3}=$ periodo $1 / 2 / 3 ; \mathbf{B O X}=$ Lexical Semantic Therapy; FIKS = Phonological Therapy. 
Tabla 1: Resultados de la revisión sistemática (continuación).

\begin{tabular}{|c|c|c|c|c|c|c|c|}
\hline \multirow{2}{*}{$\begin{array}{l}\text { Artículo } \\
\text { (autor/es, año y } \\
\text { tipo de estudio) }\end{array}$} & \multirow[b]{2}{*}{ Objetivos } & \multicolumn{3}{|c|}{ Pacientes } & \multicolumn{2}{|c|}{ Intervención logopédica } & \multirow[b]{2}{*}{ Resultados y conclusiones } \\
\hline & & $\mathbf{N}$ & Diagnóstico & $\begin{array}{l}\text { Tiempo } \\
\text { DCA }\end{array}$ & Descripción & $\begin{array}{c}\text { Frecuencia y } \\
\text { duración }\end{array}$ & \\
\hline $\begin{array}{l}\text { Woldag et al. }{ }^{49} \\
\qquad 2017 \\
\text { EC de grupos } \\
\text { paralelos, } \\
\text { aleatorio, con } \\
\text { evaluación ciega. }\end{array}$ & $\begin{array}{l}\text { Identificar el } \\
\text { componente } \\
\text { efectivo del CIAT y } \\
\text { evaluar la } \\
\text { factibilidad del SLT } \\
\text { en la etapa aguda } \\
\text { después de un } \\
\text { accidente } \\
\text { cerebrovascular. }\end{array}$ & 60 & $\begin{array}{c}\text { Afasia de } \\
\text { cualquier tipo } \\
\text { y grado, por } \\
\text { ACV. }\end{array}$ & $\begin{array}{l}\text { 18'9 días } \\
\text { de } \\
\text { media } \\
\text { (etapa } \\
\text { aguda) }\end{array}$ & $\begin{array}{l}\text { GE1: terapia grupal CIAT. } \\
\text { GE2: tto grupal convencional } \\
\text { (sin restricciones) de } \\
\text { enfoque interactivo y } \\
\text { contenido variado. } \\
\text { GC: mismo enfoque que } \\
\text { GE2, pero con sesiones } \\
\text { individuales adicionales. }\end{array}$ & $\begin{array}{c}\text { GE1 y GE2: } \\
\text { sesiones de } 3 \mathrm{~h}, 10 \\
\text { días laborales. } 30 \mathrm{~h} \\
\text { en total. } \\
\text { GC: } 2 \text { sesiones de } \\
30 \text { min/día }+4 \\
\text { sesiones de } 1 \mathrm{~h} \\
\text { durante } 10 \text { días } \\
\text { laborales. } 14 \mathrm{~h} \text { en } \\
\text { total. }\end{array}$ & $\begin{array}{l}\text { - Los tres grupos obtuvieron } \\
\text { resultados similares, aunque el } \\
\text { grupo CIAT presentó una mejor } \\
\text { calidad de la comunicación. } \\
\text { - El éxito del GC pudo deberse a las } \\
\text { sesiones individuales. } \\
\text { - En los grupos intensivos pudo } \\
\text { producirse un efecto de } \\
\text { "saturación". }\end{array}$ \\
\hline $\begin{array}{l}\text { Breitenstein et } \\
\text { al. }{ }^{50} 2017 \\
\text { EC con grupo } \\
\text { control, aleatorio, } \\
\text { con evaluación } \\
\text { ciega. }\end{array}$ & $\begin{array}{l}\text { Examinar si el } \\
\text { enfoque } \\
\text { integrativo e } \\
\text { intensivo produce } \\
\text { mejoras } \\
\text { funcionales y } \\
\text { mantenidas en } \\
\text { pacientes con } \\
\text { afasia crónica. }\end{array}$ & 156 & $\begin{array}{c}\text { Afasia de } \\
\text { cualquier tipo } \\
\text { y grado, por } \\
\text { ACV. }\end{array}$ & $\begin{array}{l}\text { Más de } 6 \\
\text { meses } \\
\text { (etapa } \\
\text { crónica) }\end{array}$ & $\begin{array}{l}\text { GE: sesiones grupales e } \\
\text { individuales con enfoque } \\
\text { combinado (lingüístico y } \\
\text { pragmático) e } \\
\text { individualizado. } \\
\text { GC: no tto (diferido). }\end{array}$ & $\begin{array}{l}\text { GE: sesiones de } 2 \mathrm{~h} \text {, } \\
5 \text { días/semana, } 3 \\
\text { semanas; }+5 \\
\text { h/semana para } \\
\text { otros tto indirecto } \\
\text { u otros. } \\
\text { GC: - }\end{array}$ & $\begin{array}{l}\text { - Mejora significativa de GE con } \\
\text { respecto a GC, que además se } \\
\text { mantuvo en el seguimiento (6 } \\
\text { meses). } \\
\text { - Algunos pacientes continuaron el } \\
\text { tto; la prolongación del tto intensivo } \\
\text { más de } 3 \text { semanas fue beneficiosa. }\end{array}$ \\
\hline $\begin{array}{l}\text { Vuksanovic et } \\
\text { al. }{ }^{51} \mathbf{2 0 1 8} \\
\text { EC de grupos } \\
\text { cruzados, } \\
\text { aleatorio, con } \\
\text { evaluación ciega. }\end{array}$ & $\begin{array}{l}\text { Comparar la } \\
\text { eficacia de la CIAT } \\
\text { y de una terapia } \\
\text { convencional sin } \\
\text { restricciones } \\
\text { aplicada de forma } \\
\text { intensiva. }\end{array}$ & 17 & $\begin{array}{l}\text { Afasia no } \\
\text { fluente (Broca } \\
\text { o } \\
\text { conducción), } \\
\text { grado medio- } \\
\text { severo, por } \\
\text { ACV }\end{array}$ & $\begin{array}{l}\text { Desde } 1 \\
\text { hasta } 52 \\
\text { semanas } \\
\text { (mezcla } \\
\text { etapas) }\end{array}$ & $\begin{array}{c}\text { G1 y G2 reciben de forma } \\
\text { cruzada dos terapias: CIAT y } \\
\text { SAT intensiva. } \\
\text { G1 recibe SAT primero, y } \\
\text { después CIAT; G2, al } \\
\text { contrario. }\end{array}$ & $\begin{array}{l}\text { Sesiones de } 1 \mathrm{~h}, 5 \\
\text { días/semana, } 4 \\
\text { semanas. } 20 \mathrm{~h} \text { en } \\
\text { total. }\end{array}$ & $\begin{array}{l}\text { - El lenguaje expresivo de todos los } \\
\text { pacientes mejoró significativamente } \\
\text { y se mantuvo en el seguimiento. } \\
\text { - La CIAT confirió un beneficio } \\
\text { adicional en denominación y en } \\
\text { producción espontánea de } \\
\text { oraciones. }\end{array}$ \\
\hline
\end{tabular}

Abreviaturas: $\mathbf{N}=$ número de pacientes; $\mathbf{D C A}=$ daño cerebral adquirido; tto = tratamiento; $\mathbf{h}=$ hora/s; $\mathbf{A C V}=$ accidente cerebrovascular; $\mathbf{G E} 1 / \mathbf{G E 2}=$ grupo experimental 1/2; GC = grupo control; G1/G2 = grupo 1/2; CIAT = Constraint-Induced Aphasia Therapy; SAT = Stimulation Aphasia Therapy . 
Tabla 1: Resultados de la revisión sistemática (continuación).

\begin{tabular}{|c|c|c|c|c|c|c|c|}
\hline \multirow{2}{*}{$\begin{array}{c}\text { Artículo } \\
\text { (autor/es, año y } \\
\text { tipo de estudio) }\end{array}$} & \multirow[b]{2}{*}{ Objetivos } & \multicolumn{3}{|c|}{ Pacientes } & \multicolumn{2}{|c|}{ Intervención logopédica } & \multirow[b]{2}{*}{ Resultados y conclusiones } \\
\hline & & $\mathbf{N}$ & Diagnóstico & $\begin{array}{c}\text { Tiempo } \\
\text { DCA }\end{array}$ & Descripción & Frecuencia y duración & \\
\hline $\begin{array}{l}\text { Stahl et al. }{ }^{52} 2018 \\
\text { EC de grupos } \\
\text { paralelos, } \\
\text { aleatorio, con } \\
\text { evaluación ciega. }\end{array}$ & $\begin{array}{l}\text { Determinar la dosis } \\
\text { diaria y duración } \\
\text { total óptimas de la } \\
\text { terapia intensiva } \\
\text { del habla y el } \\
\text { lenguaje. }\end{array}$ & 30 & $\begin{array}{l}\text { Afasia no } \\
\text { fluente, de } \\
\text { cualquier } \\
\text { grado, por } \\
\text { ACV. }\end{array}$ & $\begin{array}{l}\text { Más de } \\
\text { un año } \\
\text { (etapa } \\
\text { crónica) }\end{array}$ & $\begin{array}{l}\text { G1 y G2 } \\
\text { recibieron ILAT } \\
\text { de forma } \\
\text { idéntica. }\end{array}$ & $\begin{array}{l}\text { G1: intensiva. Sesiones } \\
\text { 4h, } 3 \text { días/semana, } 4 \\
\text { semanas. } 48 \mathrm{~h} \text { en total. } \\
\text { G1: intensidad } \\
\text { moderada. Sesiones } 2 \mathrm{~h} \text {, } \\
3 \text { días/semana, } 4 \\
\text { semanas. } 24 \mathrm{~h} \text { en total. }\end{array}$ & $\begin{array}{l}\text { - El nivel lingüístico mejora } \\
\text { notablemente en ambos grupos, } \\
\text { pero la diferencia entre ambos no } \\
\text { fue significativa. } \\
\text { - Sugieren que administrar el tto más } \\
\text { de horas diarias no aporta } \\
\text { beneficios significativos, pero sí } \\
\text { extender el tto intensivo a una } \\
\text { duración de un mes. }\end{array}$ \\
\hline $\begin{array}{c}\text { Grechuta, et al. }{ }^{53} \\
\mathbf{2 0 1 9} \\
\text { EC de grupos } \\
\text { paralelos, } \\
\text { aleatorio. }\end{array}$ & $\begin{array}{l}\text { Comprobar si una } \\
\text { adaptación } \\
\text { informática } \\
\text { (videojuego) de la } \\
\text { CIAT puede } \\
\text { conseguir unos } \\
\text { resultados } \\
\text { similares. }\end{array}$ & 17 & $\begin{array}{c}\text { Afasia no } \\
\text { fluente, grado } \\
\text { moderado- } \\
\text { severo, por } \\
\text { ACV. }\end{array}$ & $\begin{array}{l}\text { Más de } 5 \\
\text { meses } \\
\text { (etapa } \\
\text { crónica). }\end{array}$ & $\begin{array}{l}\text { G1: RGSa. } \\
\text { G2: terapia } \\
\text { logopédica } \\
\text { estándar } \\
\text { individual } \\
\text { centrada en el } \\
\text { déficit. }\end{array}$ & $\begin{array}{c}\text { Ambos grupos } \\
\text { recibieron sesiones de } \\
30-40 \text { minutos, } 5 \\
\text { días/semana, } 8 \\
\text { semanas. } 20 \mathrm{~h} \text { en total. }\end{array}$ & $\begin{array}{l}\text { - Ambos grupos mejoraron } \\
\text { significativamente; GE obtuvo } \\
\text { mejores resultados a nivel } \\
\text { pragmático, y GC a nivel léxico y de } \\
\text { ejecución verbal. } \\
\text { - En el seguimiento ambos grupos } \\
\text { conservaron los cambios. } \\
\text { - La RGSa demuestra potencial en la } \\
\text { recuperación lingüística y motora } \\
\text { tras ACV, pero se debe continuar } \\
\text { investigando. }\end{array}$ \\
\hline
\end{tabular}

Abreviaturas: $\mathbf{N}=$ número de pacientes; $\mathbf{D C A}=$ daño cerebral adquirido; tto = tratamiento; $\mathbf{h}=\mathbf{h o r a} / \mathrm{s} ; \mathbf{A C V}=$ accidente cerebrovascular; $\mathbf{G E}=$ grupo experimental; GC = grupo control; G1/G2 = grupo 1/2; ILAT = Intensive Language-Action Therapy; RGSa = Rehabilitation Gaming System for Aphasia. 


\section{DISCUSIÓN}

La meta principal de este trabajo es actualizar y organizar los conceptos sobre la intervención logopédica intensiva reciente en pacientes con afectación del lenguaje por DCA. Para ello, se ha llevado a cabo una búsqueda exhaustiva de ensayos clínicos relativos al tema pertenecientes a la última década. Aunque se esperaba encontrar un número escaso de artículos, se descubrió que la investigación sobre las terapias intensivas en pacientes afásicos es extensa. Tras aplicar los criterios de inclusión y exclusión, se seleccionaron 22 artículos para realizar la revisión sistemática. Cabe destacar que todos los artículos de la revisión sistemática están escritos en lengua inglesa.

Cabe destacar que el criterio por el que se descartó un mayor número de artículos fue el año de publicación, pues las terapias intensivas comenzaron a ser un tema de interés entre la comunidad científica a comienzos de siglo. En el estudio clásico de Pulvermüller et al. ${ }^{19}$ del año 2001, se contrastó que un tratamiento de 30 horas concentradas en 10 días en pacientes con afasia crónica era más eficaz que si dichas horas se prolongaban durante un mes. Bhogal et al. $^{28}$, en su revisión del año 2003, llegan a la conclusión de que los ensayos que proporcionaban un tratamiento intenso en un plazo breve de tiempo alcanzaban mejoras más significativas que aquellos cuyas sesiones se extendían a lo largo de un intervalo de tiempo más prolongado. Poco tiempo después, otros estudios obtuvieron resultados similares, como los de Meinzer et al., en los que se obtienen resultados muy favorables en la aplicación de la intervención logopédica intensiva en 27 pacientes crónicos ${ }^{54}$ y en el análisis de los cambios de la actividad cerebral tras la terapia ${ }^{55}$. De esta manera, se fue construyendo un marco de evidencia en favor de las terapias intensivas en la etapa crónica. Los estudios más actuales, recogidos en esta revisión sistemática, parten de estos hallazgos y se centran en aspectos más concretos y menos investigados, originando un entramado de investigación puntero, complejo y controvertido sobre el que todavía quedan diversas incógnitas por comprobar ${ }^{51}$.

Los estudios revisados en este trabajo plantean diferentes objetivos y diseños de investigación. De los 22 artículos totales, 15 comparan dos terapias intensivas, bien sea con el objetivo de identificar la dosis más adecuada ${ }^{34,42,45,52}$, de determinar el enfoque metodológico más eficaz $z^{35,37-39,41,43,44,47,51,53}$, o una combinación de ambos ${ }^{49}$; de estos 15 estudios comparativos, 10 emplean un diseño de investigación de grupos paralelos, 4 de grupos 
cruzados y 1 estudio de línea base múltiple. Los 7 artículos restantes tienen el objetivo de comprobar los beneficios del tratamiento logopédico intensivo en la etapa aguda de la afasia $^{32,33,36,48}$ o en la etapa crónica ${ }^{40,46,50}$. Para ello, controlan los resultados frente a un grupo control; uno de ellos no cuenta con grupo control $^{46}$, se trata de un estudio de caso múltiple.

En relación al tamaño muestral, solamente 4 estudios cuentan con una muestra superior o igual a 100 pacientes $32,37,48,50$, lo que supone una limitación importante. También es importante mencionar que un total de 18 estudios realizan una asignación aleatoria a los grupos experimentales o de control y 15 presentan una evaluación ciega, en la que el evaluador no sabe qué tratamiento ha recibido el paciente.

Teniendo en cuenta la popularidad de la temática, es comprensible e inevitable que existe heterogeneidad en los ensayos en cuanto al diseño, los objetivos, la muestra utilizada y el tratamiento aplicado. Doogan et al. ${ }^{18}$ comentan la dificultad que entraña, a la hora de extraer conclusiones firmes, la cantidad de variables que intervienen en el éxito de la terapia y las diferencias metodológicas entre los diferentes autores. Es por ello que, en este trabajo, se ha tratado de seleccionar una muestra de artículos relativamente homogénea, descartando los ensayos que no se centraban específicamente en la eficacia de la terapia intensiva y aquellos con poca evidencia y control de las variables.

Se discutirán los artículos revisados partiendo de los 4 objetivos planteados en este trabajo.

\section{1) Comprobar la eficacia y los beneficios de la intervención logopédica de carácter intensivo en personas con afasia.}

Centrándonos en los 22 artículos revisados, 18 33,35-39,41,43-47,49-53 de ellos han encontrado eficaces las terapias intensivas, consiguiendo mejoras significativas en las capacidades lingüísticas de los pacientes, mejoras que además se mantuvieron estables en todos los estudios que presentaron seguimiento $35,36,37,41,45,46,50,51,53$. En contraposición, únicamente destacan los estudios de Laska et al. ${ }^{32} \mathrm{y}$ de Nouwens et al. ${ }^{48}$, que no encontraron ventajas significativas entre el grupo experimental intensivo y el grupo control sin tratamiento, pero hay que tener en cuenta que estos dos ensayos estudian una muestra de pacientes en etapa aguda; estos resultados se analizarán más adelante. Los dos artículos restantes obtuvieron resultados poco concluyentes ${ }^{34,40}$. Szaflarski et al. ${ }^{40}$ atisban en su estudio cierta ventaja del 
grupo experimental intensivo frente al grupo control sin tratamiento, pero esta fue modesta. Algo similar ocurre en el ensayo de Pavão et al. ${ }^{34}$, en el que comparan los efectos de una dosis de tratamiento intensiva frente a un régimen regular, concluyendo que ambos grupos mejoraron, pero no de forma homogénea ni muy evidente. Este último estudio se analizará posteriormente con mayor profundidad.

Analizando los beneficios de las terapias intensivas, merece especial mención el estudio de Mohr et al. ${ }^{47}$, en el que se determina que la terapia intensiva de carácter pragmático-social puede disminuir considerablemente los síntomas de depresión en pacientes con afasia crónica. A su vez, 3 estudios evalúan el incremento de la calidad de vida tras la intervención de carácter intensivo mediante escalas, todos ellos con resultados favorables ${ }^{41,46,50}$.

A pesar de que la evidencia parece arrojar un potencial considerable a las terapias intensivas, ciertamente no están difundidas en la práctica logopédica común. Gunning et al. ${ }^{56}$ realizaron un estudio sobre las percepciones de los logopedas, en el que la mayoría atribuyen a los tratamientos intensivos desventajas relacionadas con la fatiga del paciente, el coste económico y la coordinación y logística de los profesionales. Es importante mencionar que únicamente uno de los 22 artículos revisados menciona que algún paciente no fue capaz de finalizar el tratamiento debido al cansancio ${ }^{48}$, mientras que 5 de ellas recalcan una adecuada tolerancia al mismo ${ }^{35-38,50}$. En cualquiera de los casos, como indica Mozeiko et al. ${ }^{44}$, lo más probable es que, en algunos casos, sea necesario y merezca la pena sobrellevar estas limitaciones para conseguir instaurar cambios significativos y duraderos en los pacientes con afectación adquirida del lenguaje.

\section{2) Determinar las diferencias existentes en las investigaciones con respecto a la dosis de la terapia intensiva en personas con afasia.}

Como se ha dicho, la intervención logopédica intensiva puede acarrear algunos inconvenientes prácticos y económicos. Por ello, como indican Mozeiko et al. ${ }^{44}$, es fundamental investigar acerca de la dosis de tratamiento suficiente para conseguir cambios significativos, con el objetivo de minimizar los costes económicos, logísticos y personales.

En esta revisión sistemática se ha observado que hay discrepancias en la noción de "intensivo" en función de los autores, tanto cualitativa como cuantitativamente. Por un lado, hay ciertos 
parámetros clave que deben diferenciarse y controlarse adecuadamente. Warren et al. ${ }^{57}$ definen cinco conceptos con el objetivo de que todas las investigaciones utilicen la misma terminología; se describirán únicamente los tres más esenciales, que son los que indican la mayoría de los artículos revisados: la frecuencia de la dosis (por día y por semana), la duración total de la intervención y la intensidad acumulativa de la intervención; en otras palabras: el número de horas por semana y por día, el número de semanas o meses durante los que se proporciona la intervención y la cantidad total de horas de intervención. En los estudios iniciales de los creadores de la $\mathrm{ClAT}^{19}$, la terapia intensiva se propuso con una alta frecuencia (entre 3 y 4 horas al día) pero con una duración reducida (10 días). Desde entonces, se ha probado la eficacia de la terapia intensiva aplicando distintas dosis.

Se analizarán los estudios cuyo objetivo era precisamente el de determinar la dosis óptima de tratamiento ${ }^{34,42,45,49,52}$. El método de estos ensayos consiste en la aplicación de una misma terapia a dos grupos experimentales, pero administrando una intensidad diferente a cada uno. Existen dos tendencias metodológicas al comparar la eficacia de dos dosis: igualar en ambos grupos el número total de horas de intervención o igualar la duración del tratamiento.

Pavão et al. ${ }^{34}$, Dignam et al. ${ }^{42}$ y Mozeiko et al. ${ }^{45}$ igualaron el número total de horas de tratamiento (100h, $48 \mathrm{~h}$ y $30 \mathrm{~h}$, respectivamente) en los dos grupos experimentales, pero variaron la frecuencia de horas por semana; es decir, se administraron a ambos grupos las mismas horas totales de terapia, pero el grupo más intensivo invirtió menos días que el menos intensivo, que se sometió a una frecuencia más distribuida. Estos tres estudios obtuvieron resultados aparentemente opuestos: Pavão et al. ${ }^{34}$ no hallaron diferencias significativas entre los dos grupos, Dignam et al. ${ }^{42}$ encontraron más eficaz la terapia menos intensiva y Mozeiko et al. ${ }^{45}$ más eficaz la terapia más intensiva. Estos resultados, que pueden parecer contradictorios, no lo son tanto si se analizan las diferentes dosis aplicadas. Mozeiko et al. ${ }^{45}$ encuentran más eficaz el tratamiento de 15 horas semanales que el de 3; a su vez, Pavão et al. ${ }^{34}$ perciben la misma eficacia en los tratamientos de 4 y de 10 horas semanales. Esto podría indicar que 4 horas semanales es una dosis aproximada de horas mínimas necesarias para hallar resultados notablemente más beneficiosos que un régimen regular. Asimismo, de forma acorde con este argumento, Dignam et al. ${ }^{42}$ determinaron ganancias superiores en el grupo que recibió 6 horas semanales frente al que recibió 16 horas, que razonaron mediante una cierta inviabilidad de la dosis más intensiva relacionada con el cansancio de los pacientes. 
A su vez, Woldag et al. ${ }^{49}$ y Stahl et al. ${ }^{52}$ también realizaron un estudio comparativo de dos grupos experimentales que recibieron dos dosis de diferente intensidad, pero en este caso lo hicieron igualando la duración del tratamiento ( 2 y 4 semanas, respectivamente); es decir, ambos grupos recibieron intervención logopédica durante el mismo periodo de tiempo, pero con frecuencias por día y semana diferentes. Las conclusiones de estos dos estudios complementan las anteriores: un tratamiento de más de 6 o 7 horas semanales parece no producir beneficios adicionales considerables, pero alargar el tratamiento intensivo más allá de dos semanas sí que es aconsejable.

En resumen, las investigaciones más recientes barajan la hipótesis de que un tratamiento moderadamente intensivo (entre 4 y 7 horas semanales) prolongado durante más de dos semanas es más beneficioso que un régimen muy intensivo (entre 15 y 20 horas semanales) aplicado durante menos de dos semanas; aunque no hay que olvidar que 18 de los ensayos clínicos de esta revisión han alcanzado resultados beneficiosos, independientemente de la dosis de intensidad aplicada, incluyendo las dosis muy intensas. Estas ideas están en consonancia con lo propuesto por Bhogal et al. ${ }^{28}$ en su revisión sistemática y suponen un hallazgo relevante teniendo en cuenta las preocupaciones sobre la viabilidad de la terapia intensiva. Sin embargo, llegar a generalizar esta intensidad moderada a la práctica sigue siendo un reto, ya que el tratamiento estándar disponible rara vez supera las 3 horas semanales, como indican Stahl et al. ${ }^{52}$ basándose en su experiencia clínica.

\section{3) Analizar la influencia de las características de los pacientes y de la afasia en la eficacia del tratamiento intensivo.}

Uno de los aspectos que complica la investigación acerca de las afasias es la heterogeneidad de las muestras, que varían en función de las características personales de los pacientes (edad y sexo), el tiempo transcurrido desde el DCA, la etiología de la afasia, la cualidad de los déficits lingüísticos y la gravedad de la afasia ${ }^{32}$. Algunos de los artículos revisados controlan estas variables con el fin de extraer conclusiones acerca del valor predictivo de las mismas en el éxito de la intervención, o bien aplican criterios de inclusión y/o de exclusión para obtener una muestra más homogénea. Por tanto, en este trabajo se analizarán dos aspectos de los ensayos revisados: el control de la homogeneidad de la muestra y las conclusiones que se han 
obtenido con respecto a la relación entre los beneficios obtenidos en la terapia intensiva y las variables relativas a los pacientes.

En primer lugar, destacan los estudios de Rose et al. ${ }^{35}$ y Sickert et al. ${ }^{37}$, que han incluido muestras heterogéneas, pero analizan la influencia de las características de los pacientes y de la afasia (edad, sexo, tipo de afasia y grado de afasia) en el éxito de la intervención. Ninguno de los dos obtuvo resultados clarificadores acerca de ninguno de los factores. Únicamente, Sickert et al. ${ }^{37}$ comentaron que la heterogeneidad de pacientes tuvo un efecto positivo en la intervención, pues aumentó la motivación y el apoyo entre los participantes.

Analizando cada variable individualmente, la etiología de la afasia es un factor bastante controlado. La gran mayoría de estudios incluyen exclusivamente individuos con afasia producida por un ACV; únicamente los estudios de Stahl et al. ${ }^{43}$ y de Mohr et al. ${ }^{47}$ (dos ensayos complementarios que cuentan con la misma muestra) aceptan individuos con otras etiologías. Ninguno de ellos encuentra diferencias significativas en la eficacia de la terapia función de la etiología. Por tanto, se necesitan futuros ensayos para aclarar si los beneficios de la terapia intensiva pueden extenderse a los pacientes con afasia de origen no vascular ${ }^{43}$.

El tiempo desde el DCA es la variable más controlada y analizada; únicamente el ensayo de Vuksanovic et al. ${ }^{51}$ incluye pacientes en su muestra sin tener en consideración esta variable. Del total de ensayos analizados, 6 se centran en la fase aguda ( 3 semanas desde el ACV, como máximo), los cuales muestran resultados contradictorios. Mientras 4 de ellos $^{33,36,41,49}$ concluyen con éxito el tratamiento, Laska et al. ${ }^{32}$ y Nouwens et al. ${ }^{48}$ no hallaron beneficios tras la terapia intensiva. Estos dos estudios son similares, pues ambos comparan la aplicación de una terapia intensiva en una muestra de pacientes en fase aguda frente a un grupo control sin tratamiento, y concluyen que el tratamiento intensivo en la etapa temprana tiene una viabilidad dudosa; Nouwens et al. ${ }^{48}$ opinan incluso que, en los primeros días tras el ACV, el logopeda debe centrarse más en orientar y asesorar al paciente y sus familiares que en rehabilitar el propio déficit lingüístico. Por otro lado, 2 ensayos ${ }^{34,37}$ escogen una muestra correspondiente con la fase subaguda (entre 1 y 3 meses, aproximadamente), ambos con resultados relativamente favorables. Finalmente, 12 artículos incluyen pacientes con afasia crónica (más de 4 meses, aproximadamente), fase en la que el éxito de la terapia intensiva 
parece estar más asegurado, pues únicamente Szaflarski et al. ${ }^{40}$ obtienen resultados poco concluyentes.

En relación con el tipo de afasia, 6 estudios restringieron la muestra a pacientes con afasia no fluente ${ }^{33,38,43,51-53}$ y 1 a pacientes con afasia fluente ${ }^{39}$. Este último es el estudio de Wilssens et al. ${ }^{39}$, que aplicó ese criterio de inclusión debido a que la mayoría de las evidencias existentes se remiten a la afasia no fluente, y obtuvo resultados igualmente favorables. Entre los 15 ensayos restantes que no controlaron el tipo de afasia de la muestra, el de Laska et al. ${ }^{32}$ es el único que denota alguna ventaja en función del tipo de afasia, en este caso, a favor de la afasia fluente. Probablemente, esta ventaja esté relacionada con la terapia empleada, que estaba basada en la comprensión verbal.

Las variables restantes parecen tener menos repercusión. Las características personales de los pacientes (sexo y edad) no han sido controladas ni analizadas por ningún ensayo, únicamente establecen todos ellos el criterio de exclusión de pacientes menores de 18 años. Finalmente, el grado de afasia parece estar poco controlado, pues la mayoría incluyen pacientes con cualquier severidad o simplemente excluyen los pacientes con afasia leve. Destaca el estudio de Van der Meulen et al. ${ }^{38}$, cuya muestra se compone únicamente de pacientes con afasia severa, consiguiendo mejoras significativas.

\section{4) Descubrir las metodologías y programas más utilizados en la intervención logopédica intensiva de personas con afasia.}

La metodología que debe adoptar la intervención logopédica intensiva para conseguir mayores beneficios es una cuestión muy polémica. Los ensayos de esta revisión emplean una gran diversidad de tratamientos logopédicos, ya sean programas específicos pautados o intervenciones estándar como las que pueden realizarse en cualquier gabinete logopédico. En los 22 artículos revisados se aplican 15 programas terapéuticos diferentes (ver Anexo II): Language Enrichment Therapy ${ }^{32}$ (LET), Lexical Semantic Therapy33,36,39,41,48 (del holandés, BOX), Mapping therapy $33,36,41$, Semantic Feature Analysis ${ }^{33,41}$ (SFA), Multimodal Stimulation Approach $^{34}$ (MSA), Multi-modality Aphasia Therapy ${ }^{35}$ (M-MAT), Constraint-Induced Aphasia Therapy (CIAT) o Intensive Language-Action Therapy (ILAT) $35-37,39-41,43-47,49,51,52$, Melodic Intonation Therapy ${ }^{38}$ (MIT), Intensive Comprehensive Aphasia Program ${ }^{42,46}$ (ICAP), Language Impairment and Functioning Therapy ${ }^{42}$ (LIFT), Naming Therapy ${ }^{36,41,4347}$ (NT), Promoting 
Aphasic Communicative Effectiveness ${ }^{44,46}$ (PACE), Phonological Therapy ${ }^{48}$ (del holandés, FIKS), Stimulation Aphasia Therapy ${ }^{51}$ (SAT) y Rehabilitation Gaming System for Aphasia ${ }^{53}$ (RGSa).

Puede observarse que los programas más populares son los del grupo CIAT (también denominado ILAT), que son las terapias intensivas por excelencia, como se ha comentado en varias ocasiones. Cabe destacar que muchos de los programas empleados en los artículos revisados no fueron diseñados originalmente como programas intensivos, pero en estas investigaciones los autores las aplican como tal; estos son los casos de las terapias BOX y PACE, entre otras, que revisando las publicaciones de los propios autores de los programas puede comprobarse que efectivamente no fueron planteadas originalmente como intensivas ${ }^{58,59}$.

Esto sucede porque el objetivo de muchos de los ensayos revisados es determinar cuál es el enfoque más beneficioso que puede adoptar una terapia intensiva, y para ello aplican una terapia diferente a dos grupos experimentales, igualando la dosis e intensidad de tratamiento. Esto sucede en 11 investigaciones, de las cuales 9 comparan la CIAT con otro tratamiento $35,37-$ $39,41,43,44,47,49,51,53$. La razón de ser de estos 9 ensayos es descubrir si el factor clave en el éxito de la CIAT es el enfoque ecológico y focalizado en el déficit lingüístico, restringiendo otras modalidades comunicativas, o si radica precisamente en la práctica masiva o intensiva. La CIAT obtuvo mejores resultados en 3 investigaciones ${ }^{43,47,51}$, pero consiguió efectos tan beneficiosos como otras metodologías en los otros 6 ensayos $^{35,37,39,41,44,49}$, por lo que las evidencias aún no son totalmente concluyentes. Lo que sí intuyen varios autores es que los pacientes que reciben la CIAT parecen tender hacia unos mejores resultados, aunque estos no alcancen la significación estadística, principalmente en las pruebas de expresión verbal, comunicación en la vida cotidiana y generalización de los aprendizajes $39,41,44,49$.

De las 11 investigaciones que comparan dos terapias diferentes aplicadas de forma intensiva, 2 no incluyen la CIAT. Uno es el estudio de Van der Meulen et al. ${ }^{38}$, que comprueba el potencial de la MIT (Terapia de Entonación Melódica, de sus siglas en inglés) frente a un tratamiento estándar de carácter intensivo, con éxito a favor de la MIT. El estudio restante es el de Grechuta et al. ${ }^{53}$, que merece una mención especial en el ámbito de las terapias intensivas más recientes, pues pone a prueba un programa informático de realidad virtual basado en los principios de la CIAT que parece tener buen potencial, aunque debe continuar investigándose. 


\section{CONCLUSIONES}

Partiendo de los objetivos planteados en este trabajo, las conclusiones obtenidas son las siguientes:

1. Las terapias intensivas en pacientes con afasia constituyen un tema de investigación puntero y controvertido desde principios de este siglo. Los primeros estudios se centraron en pacientes con afasia crónica.

2. Las investigaciones más recientes buscan concretar diversos aspectos para optimizar los resultados de los tratamientos intensivos. Estos son principalmente la dosis óptima de tratamiento, el enfoque metodológico más beneficioso y la viabilidad de la terapia intensiva en pacientes en etapa aguda.

3. La investigación sobre las terapias intensivas se caracteriza por su heterogeneidad en cuanto al diseño, la muestra de pacientes empleada y las características de la intervención aplicada.

4. La evidencia sobre el éxito de las terapias intensivas tanto en el lenguaje como en la calidad de vida es considerable; no obstante, en la práctica logopédica no están generalizadas por los elevados costes económicos, logísticos y personales que conllevan.

5. La dosis óptima del tratamiento logopédico intensivo continúa investigándose, aunque hallazgos recientes apuntan hacia un mayor beneficio de un régimen de intervención moderadamente intensivo (entre 4 y 7 horas semanales) y prolongado durante más de dos semanas.

6. El tiempo transcurrido desde el DCA hasta el comienzo del tratamiento intensivo influye en el éxito del mismo. Su eficacia está más contrastada en la etapa crónica, pero en la etapa aguda los resultados continúan siendo contradictorios.

7. Se precisan más investigaciones que evidencien si las terapias intensivas son igualmente beneficiosas en función de la etiología, el tipo y el grado de afasia y la edad de los participantes.

8. El enfoque metodológico óptimo de las terapias intensivas es una cuestión polémica. Aunque existen opiniones muy diversas y todavía existen resultados contradictorios, la CIAT parece mantenerse como la terapia intensiva con mayor nivel de evidencia. 


\section{REFERENCIAS BIBLIOGRÁFICAS}

1. Talleres FEDACE sobre Daño Cerebral Adquirido [Intrernet]. Madrid: Federación Española de Daño Cerebral FEDACE; 2007 [citado 2 de mayo de 2020]. Disponible en: https://cutt.ly/TufXK6k

2. Berthier ML, García N, Dávila G. Afasias y trastornos del habla. Medicine (Barc., Internet). 2011;10(74):5035-5041. doi: 10.1016/S0304-5412(11)70049-X

3. Martínez JM. Neurolingüística: patologías y trastornos del lenguaje. Rev. digit. univ. [Internet]. 2008 [citado 2 de mayo de 2020];9(12). Recuperado a partir de https://n9.cl/iaol

4. American Speech-Language-Hearing Asociation [Internet]. Aphasia: Overview - ASHA; 2017. [citado 2 de mayo de 2020]. Recuperado a partir de: https://cutt.ly/EufSLGN

5. González P, González, B. Afasia. De la teoría a la práctica. México: Editorial Médica Panamericana; 2012.

6. Peña-Casanova J, Manero RM, Diéguez F, Sánchez G. Afasias. En: Peña-Casanova J. Manual de logopedia. Barcelona: Elsevier Masson; 2013. P. 309-352.

7. Brogan E, Ciccone N, Godecke E. Treatment Fidelity in aphasia randomised controlled trials. Aphasiology. 2019;33(7):759-779. doi: 10.1080/02687038.2019.1576442

8. Hillis AE. Aphasia: Progress in the Last Quarter of a Century. Neurology. 2007;69(2):200-13.

doi: 10.1212/01.wnl.0000265600.69385.6f

9. Brady MC, Kelly H, Godwin J, Enderby P, Campbell P. Speech and language therapy for aphasia following stroke (Review). Cochrane Database Syst Rev. 2016;6:CD000425. doi: 10.1002/14651858.CD000425.pub4

10. Berthier ML. Poststroke Aphasia: Epidemiology, Pathophysiology and Treatment. Drugs Aging. 2005;22(2):163-182. doi: 10.2165/00002512-20052202000006

11. Watila MM, Balarabe SA. Factors predicting post-stroke aphasia recovery. J Neurol Sci. 2015;352(1-2):12-8. doi: 10.1016/j.jns.2015.03.020

12. Martínez EO, Pino M, Broche $Y$. Perspectivas científicas en la investigación de la afasia. Consideraciones teóricas. Encuentros. 2015;13(1):75-84. doi: 10.15665/re.v13i1.350

13. Martínez EO, Rodríguez $Y$, Pino $M$, Pardo VM. Procesamiento preléxico y tipo de afasia diagnosticada según clasificaciones sindrómicas. Evidencia neurolingüísticas. Neuropsicol lat am. 2016;8(3):52-63. doi: 2075-9479

14. Ardilla A. Las afasias. Miami. Florida International University; 2006.

15. Ardilla A. Aphasia Handbook. Miami. Florida International University; 2014.

16. De Noreña D, Ríos M, Bombín I, Sánchez I, García A, Tirapu J. Efectividad de la rehabilitación neuropsicológica en el daño cerebral adquirido (I): atención, velocidad de procesamiento, memoria y lenguaje. Rev Neurol. 2010;51(11):687-698. Doi :10.33588/rn.5111.2009652

17. Saikaley M, Iruthayarajah J, Orange J, Welch-West P, Salter K, Macaluso S, et al. Chapter 14: Aphasia and Apraxia Rehabilitation [Intrernet]. Ontario: 19th edition of the Evidence-Based Review of Stroke Rehabilitation; 2018 [citado 22 de mayo de 2020]. Disponible en: https://url2.cl/S7rlP
18. Doogan C, Dignam J, Copland D, Leff A. Aphasia Recovery: When, How and Who to Treat?. Curr Neurol Neurosci Rep. 2018; 18(12):90. doi: 10.1007/s11910-018-0891-x

19. Pulvermüller F, Neininger B, Elbert T, Mohr B, Rockstroh B, Koebbel $P$ et al. Constraint-Induced Therapy of Chronic Aphasia After Stroke. Stroke. 2001;32(7):1621-1626. doi: 10.1161/01.STR.32.7.1621

20. Berube S, Hillis AE. Advances and Innovations in Aphasia Treatment Trials. Stroke. 2019;50(10):2977-2984. doi: 10.1161/STROKEAHA.119.025290

21. Pulvermüller F, Berthier ML. Aphasia therapy on a neurosciencis basis. Aphasiology. 2008;22(6):563-599. doi: 10.1080/02687030701612213

22. Difrancesco S, Pulvermüller, Mohr B. Intensive languageaction therapy (ILAT): The metods. Aphasiology. 2012;26(11):1317-1351. 10.1080/02687038.2012.705815

23. Cherney LR, Patterson JP, Raymer A, Frymark T. EvidenceBased Systematic Review: Effects of Intensity of Treatment and Constraint-Induced Language Therapy for Individuals With Stroke-Induced Aphasia. J Speech Lang Hear Res. 2008;51(5):1282-99. doi: 10.1044/1092-4388(2008/070206)

24. Zhang J, Yu J, Bao Y, Xie Q, Xu Y et al. Constraint-induced aphasia therapy in post-stroke aphasia rehabilitation: A systematic review and meta-analysis of randomized controlled trials. PLoS One. 2017;12(8):e0183349. doi: 10.1371/journal.pone.0183349

25. Berthier ML, Green C, Juárez-Ruíz R, Lara JP, Pulvermüller F. REGIA. Rehabilitación Grupal Intensiva de la Afasia. Madrid: TEA Ediciones. 2014.

26. Egorova N, Shtyrov $Y$, Pulvermüller F. Brain basis of communicative actions in language. Neuroimage. 2015;125:857-867.

27. Berthier ML, Green C, Lara JP, Higueras C, Barbancho. Memantine and Constraint-Induced Aphasia Therapy in Chronic Poststroke Aphasia. Ann Neurol. 2009;65(5):577585. doi: 10.1002/ana.21597.

28. Bhogal SK, Teasell R, Speechley M. Intensity of aphasia treatment, Impact on Recovery. Stroke. 2003;34(4):987993. doi: 10.1161/01.STR.0000062343.64383.D0

29. Rose ML, Cherney LR, Worral LE. Intensive Comprehensive Aphasia Programs: An International Survey of Practice. Top Stroke Rehabil. 2013;20(5):379-387. doi: 10.1310/tsr2005379.

30. Rose ML, Attard, M. Multi-modality aphasia therapy (MMAT): A procedural manual. Melbourne: La Trobe University; 2011.

31. Jovell AJ, Navarro-Rubio MD. Evaluación de la evidencia científica. Med Clin (Barc) 1995;105:740-3.

32. Laska AC, Kahan T, Hellblom A, Murray M, Von Arbin M. A Randomized Controlled Trial on Very Early Speech and Language Therapy in Acute Stroke Patients with Aphasia. Cerebrovasc Dis Extra. 2011;1(1):66-74. doi: 10.1159 / 000329835

33. Godecke E, Hird K, Lalor EE, Rai T, Phillips MR. Very early poststroke aphasia therapy: a pilot randomized controlled efficacy trial. Int J Stroke. 2012;7(8):635-44. doi: 10.1111/j.1747-4949.2011.00631.x 
34. Pãvao I, Leal G, Fonseca I, Farrajota L, Fonseca J, et al. A randomized, rater-blinded, parallel trial of intensive speech therapy in sub-acute post-stroke aphasia: the SP-I-R-IT study. Int J Lang Commun Disord. 2013;48(4):421-431. doi: 10.1111/1460-6984.12018

35. Rose ML, Attard MC, Mok Z, Lanyon LE, Foster AM. Multimodality aphasia therapy is as efficacious as a constraintinduced aphasia therapy for chronic aphasia: A phase 1 study. Aphasiology. 2013;27(8):938-971. doi: 10.1080/02687038.2013.810329

36. Godecke E, Ciccone NA, Granger AS, Rai T, West D, Cream $A$, et al. A comparison of aphasia therapy outcomes before and after a Very Early Rehabilitation programme following stroke. Int J Lang Commun Disord. 2014;49(2):149-161. doi: 10.1111 / 1460-6984.12074

37. Sickert A, Anders LC, Münte TF, Sailer M. Constraintinduced Aphasia Therapy Following Sub-Acute Stroke: A Single-Blind, Randomised Clinical Trial of a Modified Therapy Schedule. J Neurol Neurosurg Psychiatry. 2014;85(1):51-5. doi: doi: 10.1136 / jnnp-2012-304297

38. Van der Meulen I, Van de Sandt-Koenderman WM, Heijenbrok-Kal MH, Visch-Brink EG, Ribbers GM. The Efficacy and Timing of Melodic Intonation Therapy in Subacute Aphasia. Neurorehabil Neural Repair. 2014;28(6):536-544. doi: 10.1177/1545968313517753

39. Wilssens I, Vandenborre D, van Dun K, Verhoeven J, VischBrink E, Mariën P. Constraint-Induced Aphasia Therapy Versus Intensive Semantic Treatment in Fluent Aphasia. Am J Speech Lang Pathol. 2015;24(2):281-94. doi: 10.1044/2015_AJSLP-14-0018

40. Szaflarski JP, Ball AL, Vannest J, Dietz AR, Allendorfer JB, Martin AN, et al. Constraint-Induced Aphasia Therapy for Treatment of Chronic Post-Stroke Aphasia: A Randomized, Blinded, Controlled Pilot Trial. Med Sci Monit. 2015;24(21):2861-9. doi: 10.12659 / MSM.894291

41. Ciccone N, West D, Cream A, Cartwright J, Rai T, Granger A, et al. Constraint-induced aphasia therapy (CIAT): a randomised controlled trial in very early stroke rehabilitation. Aphasiology. 2016;30(5):566-584. doi: 10.1080/02687038.2015.1071480

42. Dignam J; Copland D, McKinnon E, Burfein P, O'Brien K, Farrell $A$, et al. Intensive Versus Distributed Aphasia Therapy: A Nonrandomized, Parallel-Group, DosageControlled Study. Stroke. 2015;46(8):2206-2211. doi: 10.1161/STROKEAHA.115.009522

43. Stahl B, Mohr B, Dreyer FR, Lucchese G, Pulvermüller F. Using Language for Social Interaction: Communication Mechanisms Promote Recovery From Chronic Non-Fluent Aphasia. Córtex. 201;85:90-99. doi: 10.1016/j.cortex.2016.09.021

44. Kurland J, Stanek EJ, Stokes P, Li M, Andrianopoulos M. Intensive Language Action Therapy in Chronic Aphasia: A Randomized Clinical Trial Examining Guidance by Constraint. Am J Speech Lang Pathol. 2016;25(4S):S798S812. doi: 10.1044/2016_AJSLP-15-0135

45. Mozeiko J, Coelho CA, Myers EB. The role of intensity in constraint-induced language therapy for people with chronic aphasia. Aphasiology. 2016;30(4): 339-363. doi: 10.1080/02687038.2015.1070949

46. Hoover EL, Caplan DN, Waters GS, Carney A. Communication and Quality of Life Outcomes From an Interprofessional Intensive, Comprehensive, Aphasia
Program (ICAP). Top Stroke Rehabil. 2017;24(2):82-90. doi: 10.1080/10749357.2016.1207147

47. Mohr B, Stahl B, Berthier ML, Pulvermüller F. Intensive Communicative Therapy Reduces Symptoms of Depression in Chronic Nonfluent Aphasia. Neurorehabil Neural Repair. 2017;31(12):1053-1062. doi: 10.1177/1545968317744275

48. Nouwens F, de Lau LM, Visch-Brink EG, van de SandtKoenderman WM, Lingsma HF, Goosen S, et al. Efficacy of Early Cognitive-Linguistic Treatment for Aphasia Due to Stroke: A Randomised Controlled Trial (Rotterdam Aphasia Therapy Study-3). Eur Stroke J. 2017;2(2):126-136. doi: 10.1177/2396987317698327

49. Woldag H, Voigt N, Bley M, Hummelsheim H. ConstraintInduced Aphasia Therapy in the Acute Stage: What Is the Key Factor for Efficacy? A Randomized Controlled Study. Neurorehabil Neural Repair. 2017;31(1):72-80. doi: 10.1177/1545968316662707

50. Breitenstein C, Grewe T, Flöel A, Ziegler W, Springer L, Martus $P$, et al. Intensive Speech and Language Therapy in Patients With Chronic Aphasia After Stroke: A Randomised, Open-Label, Blinded-Endpoint, Controlled Trial in a HealthCare Setting. Lancet. 2017;389(10078):1528-1538. doi: 10.1016/S0140-6736(17)30067-3

51. Vuksanović J, Milovanović T, Konstantinović L, Filipović SR. Effect of Type of Language Therapy on Expressive Language Skills in Patients With Post-Stroke Aphasia. Int J Lang Commun Disord. 2018;53(4):825-835. doi: 10.1111/14606984.12390

52. Stahl B, Mohr B, Büscher V, Dreyer FR, Lucchese G, Pulvermüller F. Efficacy of Intensive Aphasia Therapy in Patients With Chronic Stroke: A Randomised Controlled Trial. J Neurol Neurosurg Psychiatry. 2018;89(6):586-592. doi: 10.1136/jnnp-2017-315962

53. Grechuta K, Rubio B, Espín R, Usabiaga T, Molina B, Mohr B. Augmented Dyadic Therapy Boosts Recovery of Language Function in Patients With Nonfluent Aphasia. Stroke. 2019;50(5):1270-1274.

doi: 10.1161/STROKEAHA.118.023729

54. Meinzer M, Djunda D, Barthel G, Elbert T, Rockstroh B. Long-term Stability of Improved Language Functions in Chronic Aphasia After Constraint-Induced Aphasia Therapy. Stroke. 2005;36(7):1462-1466. doi: 10.1161/01.STR.0000169941.29831.2a

55. Meinzer M, Elbert T, Wienbruch C, Djundja D, Barthel G, Rockstroh B. BMC Biol. 2004;2(20). doi: 10.1186/17417007-2-20

56. Gunning D, Wenke R, Ward EC, Chalk S, Lawrie M, Romano $M$ et al. Clinician's perceptions of delivering new models of high intensity aphasia treatment. Aphasiology. 2017;31(4):406-426. doi: 10.1080/02687038.2016.1236359

57. Warren SF, Fey ME, Yoder PJ. Differential Treatment Intensity Research: A Missing Link to Creating Optimally Effective Communication Interventions. Ment Retard Dev Disabil Res Rev. 2007;13(1):70-77. doi: 10.1002/mrdd.20139

58. Visch-Brink EG, Bajema IM, Sandt-Koenderman V. Clinical forum: lexical semantic therapy: BOX. Aphasiology 1997;11:1057-115.

59. Davis GA. PACE revisited. Aphasiology. 2005;19:21-38. 


\section{ANEXOS}

Anexo I. Principales características de los síndromes afásicos ${ }^{5}$

\begin{tabular}{|c|c|c|c|}
\hline & Afasia de Broca & Afasia de Wernicke & Afasia de conducción \\
\hline Expresión & $\begin{array}{l}\text { Lenguaje no fluido, } \\
\text { lento, segmentado, } \\
\text { producido con esfuerzo. }\end{array}$ & $\begin{array}{l}\text { Lenguaje fluido, en } \\
\text { ocasiones logorréico. } \\
\text { Parafasias semánticas, } \\
\text { neologismos y jerga. }\end{array}$ & $\begin{array}{l}\text { Lenguaje fluido con } \\
\text { cierta anomia. }\end{array}$ \\
\hline $\begin{array}{l}\text { Fonética y } \\
\text { fonología }\end{array}$ & $\begin{array}{l}\text { Disartria, parafasias } \\
\text { fonológicas. }\end{array}$ & $\begin{array}{l}\text { No hay problemas } \\
\text { fonéticos. } \\
\text { Parafasias fonológicas. }\end{array}$ & $\begin{array}{l}\text { Fonética bien. } \\
\text { Parafasias fonológicas. } \\
\text { Conductas de } \\
\text { aproximación. }\end{array}$ \\
\hline Morfosintaxis & $\begin{array}{l}\text { Agramatismo (lenguaje } \\
\text { telegráfico). }\end{array}$ & $\begin{array}{l}\text { Buena estructuración } \\
\text { sintáctica. } \\
\text { Paragramatismo } \\
\text { ocasional. }\end{array}$ & Normal. \\
\hline Discurso & $\begin{array}{l}\text { Transmisión de } \\
\text { información variable, } \\
\text { de nula a buena. }\end{array}$ & $\begin{array}{l}\text { Discurso vacio, carente } \\
\text { de información, fuera } \\
\text { del contexto en el que } \\
\text { se produce. }\end{array}$ & $\begin{array}{l}\text { Buena transmisión de } \\
\text { información. }\end{array}$ \\
\hline Prosodia & Aprosodia. & Normal. & Normal. \\
\hline Comprensión & $\begin{array}{l}\text { Afectada en el nivel } \\
\text { morfosintáctico. }\end{array}$ & $\begin{array}{l}\text { Afectada en todos los } \\
\text { niveles, especialmente } \\
\text { en el léxico. }\end{array}$ & $\begin{array}{l}\text { Afectada en el nivel } \\
\text { morfosintáctico. }\end{array}$ \\
\hline Denominación & $\begin{array}{l}\text { Anomia. Problemas } \\
\text { fonéticos y fonológicos. } \\
\text { Problema de acceso. }\end{array}$ & $\begin{array}{l}\text { Parafasias. } \\
\text { Neologismos. } \\
\text { Circunloquios. } \\
\text { Problema de } \\
\text { desintegración. }\end{array}$ & $\begin{array}{l}\text { Parafasias fonológicas, } \\
\text { conductas de } \\
\text { aproximación.Problema } \\
\text { de acceso. }\end{array}$ \\
\hline Repetición & $\begin{array}{l}\text { Problemas fonéticos y } \\
\text { fonológicos. Repetición } \\
\text { telegráfica. }\end{array}$ & $\begin{array}{l}\text { Parafasias. } \\
\text { Neologismos. Jerga. } \\
\text { Es probable que } \\
\text { los pacientes no } \\
\text { comprendan la tarea. }\end{array}$ & $\begin{array}{l}\text { Siempre afectada. } \\
\text { Conductas de } \\
\text { aproximación y } \\
\text { parafasias fonológicas. }\end{array}$ \\
\hline Lectura & $\begin{array}{l}\text { Lenta, entrecortada, } \\
\text { agramática. } \\
\text { Problemas fonéticos y } \\
\text { fonológicos. } \\
\text { Mala comprensión. }\end{array}$ & $\begin{array}{l}\text { Neologismos y } \\
\text { parafasias. } \\
\text { Mala comprensión. }\end{array}$ & $\begin{array}{l}\text { Conductas de } \\
\text { aproximación y } \\
\text { parafasias. } \\
\text { Buena comprensión } \\
\text { (en especial en lectura } \\
\text { silente). }\end{array}$ \\
\hline Escritura & $\begin{array}{l}\text { Problemas motores. } \\
\text { Mismos errores que en } \\
\text { el lenguaje espontáneo. }\end{array}$ & Jerga agráfica. & $\begin{array}{l}\text { Paragrafias literales. } \\
\text { Los automatismos se } \\
\text { conservan. }\end{array}$ \\
\hline $\begin{array}{l}\text { Trastornos } \\
\text { asociados }\end{array}$ & $\begin{array}{l}\text { Hemiplejia o } \\
\text { hemiparesia derecha. }\end{array}$ & Ninguno característico. & $\begin{array}{l}\text { Hemiparesia y apraxia } \\
\text { ideatoria. }\end{array}$ \\
\hline
\end{tabular}


Anexo I. Principales características de los síndromes afásicos 5 (continuación)

\begin{tabular}{|c|c|c|c|}
\hline & $\begin{array}{c}\text { Afasia motora } \\
\text { transcortical }\end{array}$ & $\begin{array}{c}\text { Afasia sensorial } \\
\text { transcortical }\end{array}$ & $\begin{array}{l}\text { Afasia mixta } \\
\text { transcortical }\end{array}$ \\
\hline Expresión & $\begin{array}{l}\text { Lenguaje no fluido, } \\
\text { lento con esterotipos y } \\
\text { ecolalia. }\end{array}$ & $\begin{array}{l}\text { Lenguaje fluido. } \\
\text { Ecolalia. Parafasias } \\
\text { semánticas y } \\
\text { neologismos. }\end{array}$ & $\begin{array}{l}\text { Lenguaje no fluido. } \\
\text { Mutismo. Ecolalia. } \\
\text { Puede haber lenguaje } \\
\text { automático. }\end{array}$ \\
\hline $\begin{array}{l}\text { Fonética y } \\
\text { fonología }\end{array}$ & $\begin{array}{l}\text { Fonética conservada. } \\
\text { Parafasias fonológicas } \\
\text { ocasionales. }\end{array}$ & $\begin{array}{l}\text { Buena ejecución } \\
\text { motora. } \\
\text { Parafasias semánticas, } \\
\text { neologismos y jerga. }\end{array}$ & $\begin{array}{l}\text { La articulación puede } \\
\text { estar conservada. }\end{array}$ \\
\hline Morfosintaxis & $\begin{array}{l}\text { Simplificación } \\
\text { sintáctica. }\end{array}$ & Buena. & ....... \\
\hline Discurso & $\begin{array}{l}\text { Afectado. Transmite } \\
\text { poca información. }\end{array}$ & Carente de información. & ....... \\
\hline Prosodia & Aprosodia. & Conservada. & ......... \\
\hline Comprensión & $\begin{array}{l}\text { Afectada en el nivel } \\
\text { morfosintáctico. }\end{array}$ & $\begin{array}{l}\text { Afectada en todos los } \\
\text { niveles. }\end{array}$ & $\begin{array}{l}\text { Afectada en todos los } \\
\text { niveles. }\end{array}$ \\
\hline Denominación & $\begin{array}{l}\text { Perseveraciones. } \\
\text { Problema de acceso. }\end{array}$ & Parafasias semánticas. & $\begin{array}{l}\text { Muy disminuida. } \\
\text { Neologismos y } \\
\text { estereotipos. }\end{array}$ \\
\hline Repetición & $\begin{array}{l}\text { Buena, Perseveraciones } \\
\text { y parafasias fonológicas } \\
\text { ocasionales. }\end{array}$ & Buena sin comprensión. & Buena sin comprensión. \\
\hline Lectura & $\begin{array}{l}\text { Mínimamente afectada. } \\
\text { Buena comprensión. }\end{array}$ & $\begin{array}{l}\text { Parafasias y } \\
\text { neologismos. } \\
\text { Mala comprensión. }\end{array}$ & Alexia severa. \\
\hline Escritura & $\begin{array}{l}\text { Simplificación } \\
\text { sintáctica, } \\
\text { perseveraciones. } \\
\text { Problemas motores. } \\
\end{array}$ & Jerga agráfica. & Agrafia severa. \\
\hline $\begin{array}{l}\text { Trastornos } \\
\text { asociados }\end{array}$ & $\begin{array}{l}\text { Hemiplejia. } \\
\text { Hemiparesia. }\end{array}$ & $\begin{array}{l}\text { Heminegligencia } \\
\text { derecha. }\end{array}$ & $\begin{array}{l}\text { Hemiplejia, } \\
\text { hemihipoestesia. }\end{array}$ \\
\hline
\end{tabular}


Anexo I. Principales características de los síndromes afásicos 5 (continuación)

\begin{tabular}{|c|c|c|}
\hline & Afasia anómica & Afasia global \\
\hline Expresión & $\begin{array}{l}\text { Lenguaje fluido, interrumpido por } \\
\text { pausas para buscar palabras. }\end{array}$ & $\begin{array}{l}\text { Lenguaje no fluido. Mutismo. } \\
\text { Puede haber estereotipos o } \\
\text { lenguaje automático. }\end{array}$ \\
\hline Fonética y fonología & Normales. & -.--- \\
\hline Morfosintaxis & Normal. & --.-- \\
\hline Discurso & Normal. & ----- \\
\hline Prosodia & Normal. & $-\cdots$ \\
\hline Comprensión & Normal. & Afectada en todos los niveles. \\
\hline Denominación & $\begin{array}{l}\text { Afectada, especialmente en } \\
\text { palabras abstractas y de baja } \\
\text { frecuencia. Problema de acceso. }\end{array}$ & $\begin{array}{l}\text { Balbuceos ininteligibles y } \\
\text { estereotipos. }\end{array}$ \\
\hline Repetición & Normal. & $\begin{array}{l}\text { Balbuceos o estereotipos. } \\
\text { Probable repetición de vocales o } \\
\text { de sílabas. }\end{array}$ \\
\hline Lectura & Normal. & Alexia severa. \\
\hline Escritura & Normal con anomia. & $\begin{array}{l}\text { Agrafia severa complicada por el } \\
\text { problema motor. }\end{array}$ \\
\hline Trastornos asociados & Ninguno característico. & $\begin{array}{l}\text { Hemiplejia, apraxia izquierda y } \\
\text { alteraciones sensitivas. }\end{array}$ \\
\hline
\end{tabular}


Anexo II. Listado de terapias aplicadas en los ensayos clínicos de la revisión sistemática

- Language Enrichment Therapy ${ }^{32}$ (LET). Programa jerarquizado y pautado centrado en comprensión y denominación. Es el programa específico de intervención logopédica más utilizado en el escenario clínico de los países escandinavos.

- Lexical Semantic Therapy ${ }^{33,36,39,41,48}$ (del holandés, BOX). Programa logopédico léxicosemántico de origen holandés centrado en la interpretación de palabras, frases y textos escritos, con una variedad de tareas destinadas a mejorar el procesamiento semántico.

- Mapping therapy ${ }^{33,36,41}$. Programa de tratamiento logopédico basado en tareas sintácticas que concibe el agramatismo como trastorno central de las personas con afasia, causante de las dificultades para producir y comprender las frases.

- Semantic Feature Analysis ${ }^{33,36,41}$ (SFA). Técnica diseñada para la rehabilitación de la anomia en pacientes con afasia.

- Multimodal Stimulation Approach ${ }^{34}$ (MSA). Terapia de estimulación lingüística estándar de complejidad creciente, en la que cada modalidad lingüística se utiliza para estimular otra. Está basado en la facilitación y la motivación.

- Multi-modality Aphasia Therapy ${ }^{35}$ (M-MAT). Terapia logopédica de carácter social e intensivo que aboga por el empleo de otras modalidades comunicativas como medio para rehabilitar el habla, sin restricciones.

- Constraint-Induced Aphasia Therapy (CIAT) o Intensive Language-Action Therapy (ILAT) 35-37,39-41,43-47,49,51,52. Programa específico de intervención logopédica en afasias basado en la aplicación intensiva, el enfoque pragmático-social y la restricción de cualquier modalidad comunicativa que no sea la expresión oral.

- Melodic Intonation Therapy ${ }^{38}$ (MIT): terapia focalizada en la producción oral mediante la entonación melódica y el ritmo.

- Intensive Comprehensive Aphasia Program ${ }^{42,46}$ (ICAP). Programas interdisciplinares de carácter intensivo destinados a personas con afasia que pretenden abarcar diversas áreas, tales como lenguaje y comunicación, socialización, factores psicológicos y personales y el entorno del paciente. Algunos también incluyen disciplinas como fisioterapia, terapia ocupacional y nutrición. 
Anexo II. Listado de terapias aplicadas en los ensayos clínicos de la revisión sistemática (continuación)

- Language Impairment and Functioning Therapy 42 (LIFT). Es un programa de tipo ICAP que incluye diversas áreas de intervención (déficit lingüístico, terapia comunicativafuncional, programas informáticos, sesiones de asesoramiento...).

- Naming Therapy ${ }^{36,41,4347}$ (NT). Terapia de enfoque neurocognitivo específicamente diseñada para la rehabilitación de la denominación.

- Promoting Aphasic Communicative Effectiveness ${ }^{44,46}$ (PACE). Terapia de enfoque pragmático-social que permite el uso de otras modalidades de comunicación con el objetivo final de mejorar el lenguaje hablado.

- Phonological Therapy ${ }^{48}$ (del holandés, FIKS). Programa de origen holandés centrado en la rehabilitación fonológica.

- Stimulation Aphasia Therapy ${ }^{51}$ (SAT). Técnica terapéutica convencional basada en la idea de que la persona con daño cerebral no ha perdido la función lingüística, sino que tiene dificultades para acceder a ella. Utiliza técnicas como la facilitación y la disociación automático-voluntario.

- Rehabilitation Gaming System for Aphasia ${ }^{53}$ (RGSa). Protocolo de entrenamiento lingüístico diario diádico, por parejas, inspirado en la ILAT, que tiene como soporte un programa informático interactivo de realidad virtual. 